Check for updates

Cite this: Mater. Adv., 2021, 2, 3790

Received 22nd March 2021 Accepted 23rd May 2021

DOI: $10.1039 / \mathrm{d} 1 \mathrm{ma00244a}$

rsc.li/materials-advances

\section{Metal-organic frameworks and zeolite materials as active fillers for lithium-ion battery solid polymer electrolytes}

\author{
João C. Barbosa, (D) ab Renato Gonçalves, (D) Carlos M. Costa, (D) *ad \\ Verónica de Zea Bermudez, (DD ${ }^{\mathrm{b}}$ Arkaitz Fidalgo-Marijuan, (D) ${ }^{\mathrm{e}}$ Qi Zhang (D) ef and \\ Senentxu Lanceros-Méndez (D) *ef
}

\begin{abstract}
The efforts to decarbonize the economies, with particular focus on renewable energies, must be accompanied by the development of more efficient and environmentally friendlier energy storage systems. In this context, all solid-state batteries emerge as one of the most promising candidates for this purpose due to their potentially higher energy density and improved safety with respect to conventional systems. With this objective, the development of solid electrolytes, with high ionic conductivity and low interfacial resistance, is a critical step to achieve the needed performances of all solid-state batteries. The three-component approach for composite solid polymer electrolytes (SPEs), which relies on the use of one polymer and two complementary fillers, attracted a great interest in recent years, due to the possibility of incorporating different fillers to impart simultaneously distinct properties to the SPEs, such as enhanced ionic conductivity and improved mechanical stability. Microporous materials are an effective option for application in this technology, due to their thermal and mechanical stability, as well as their tuneable structure, high porosity and surface area, which make them suitable materials to adsorb and encapsulate other components. In this work, the main advantages and disadvantages of SPEs are discussed, together with the critical issues to be addressed in the near future, namely the low room temperature ionic conductivity and the interfacial compatibility issues. Some solutions are proposed, with special focus on microporous materials, particularly metal-organic frameworks (MOFs) and zeolites. Their main properties and advantages for application in this field are presented. A comprehensive stateof-the-art of this exciting topic of research is also provided, highlighting the most recent advances in the area.
\end{abstract}

\section{Introduction}

Nowadays, the world is facing relevant issues associated with the continuous growth of the population and the increasing in living standards. These factors led to the use of more natural resources and to an increased energy consumption, which in turn leads to an increased pressure on natural resources due to over exploration and environmental damage, particularly climate change, that is essentially caused by the world's reliance on fossil fuels to run the economies. ${ }^{1}$ The transition to highly efficient and environmentally friendlier systems for energy production is needed to constrain climate change and to support sustainable population growth, warranting reliable and affordable energy for everyone without compromising the environment. The United Nations is one of the main drivers of this transition, with two of their 17 goals for sustainable development until 2030 directly related to this thematic ( 7 - affordable and clean energy; 13 - climate action). ${ }^{2}$ The decarbonization of the economies, with reliance in renewable energy sources is one of the main strategies adopted by the governments to overcome the dependence on fossil fuels. However, renewable energies, such as wind or sun, are

\footnotetext{
${ }^{a}$ Center of Physics, University of Minho, 4710-058 Braga, Portugal. E-mail: cmscosta@fisica.uminho.pt

${ }^{b}$ Department of Chemistry and CQ-VR, University of Trás-os-Montes e Alto Douro, 5000-801 Vila Real, Portugal

${ }^{c}$ Center of Chemistry, University of Minho, 4710-058 Braga, Portugal

${ }^{d}$ Institute of Science and Innovation for Bio-Sustainability (IB-S), University of Minho, 4710-053 Braga, Portugal

${ }^{e}$ BCMaterials, Basque Center for Materials, Applications and Nanostructures, UPV/EHU Science Park, 48940 Leioa, Spain. E-mail: senentxu.lanceros@bcmaterials.net

${ }^{f}$ Ikerbasque, Basque Foundation for Science, 48009 Bilbao, Spain
} 
intermittent, and are dependent on time or weather conditions to be effective. ${ }^{3}$ This leads to the necessity of developing efficient and environmentally friendlier energy storage systems in the years to come, to store the energy that is not used during the high production hours, and that can be used later, in the hours of higher demand. ${ }^{4}$ In this context, batteries emerge as an effective solution for these issues.

A battery is a device that is able to convert chemical energy into electrical energy, and vice versa, in a closed system. ${ }^{5}$ The first battery was developed by Alessandro Volta in 1800, using zinc and silver electrodes, and brine-soaked cloth as separator. ${ }^{6}$ Lithium technology only started to be developed in the 20th century. ${ }^{7}$ Early in 1972, Michel Armand ${ }^{8}$ mentioned the general properties needed for an intercalation electrode and provided the first report on a solid-state battery (SSB). The first commercial lithium ion $\left(\mathrm{Li}^{+}\right)$battery (LIB) was developed in 1991, by Sony. ${ }^{9}$ Nowadays, LIBs are the most worldwide used devices for energy storage purposes due to their high energy density and long cycle life, allowing the production of light and small devices without jeopardizing battery capacity. ${ }^{10}$ A common LIB is composed by three basic components: two electrodes (cathode and anode) and a separator, usually soaked in an electrolyte solution. The electrodes, that are deposited on aluminum (cathode) and copper (anode) foils, are composed of an active material, a conductive material, and a binder. The separator is placed between the electrodes and is usually a polymeric porous membrane. ${ }^{11}$

The separator plays a key role in the battery, as it works as a physical barrier between the electrodes, avoiding the occurrence of short circuits during the operation. A good separator must possess thermal, mechanical and thermal stability ${ }^{12}$ and must show high electronic resistance and high ionic conductivity to the $\mathrm{Li}^{+}$flow. ${ }^{13}$ The most widely used materials for separators are polymers, such as poly(ethylene) (PE), poly(propylene) (PP) or poly(vinylidene fluoride) (PVDF). These polymers meet the requirement of high electronic resistance but lack the necessary high ionic conductivity.

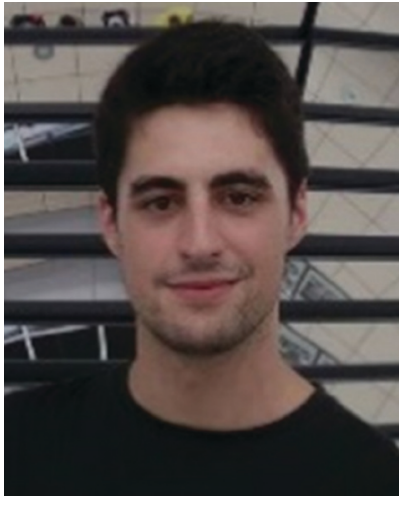

João C. Barbosa
João C. Barbosa graduated in Environmental Sciences and Technologies in 2015 at University of Porto, Portugal, and obtained a Master degree in Environmental Sciences and Technologies - Energy Specialization in 2017 at University of Minho, Portugal. Actually, he is working on his PhD in Materials Engineering at the University of Minho, Portugal. He is working in the area of Energy Storage, in particular in the development of solid polymer electrolytes for lithium ion batteries.

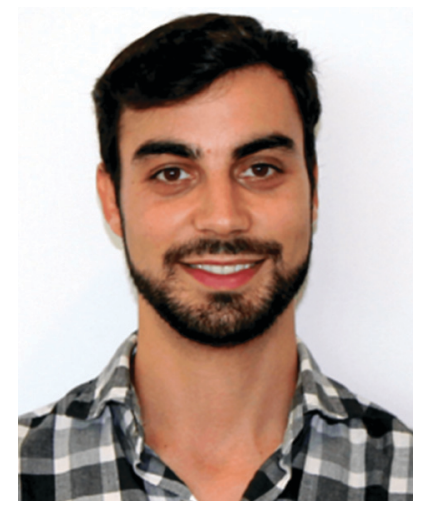

Renato Gonçalves

Renato Gonçalves graduated in Chemistry in 2009, in 2011 obtained a Master degree in Characterization Techniques and Chemistry Analysis and in 2017 obtained the PhD in Materials Engineering, all at the University of Minho, Portugal. At this moment, he is working at Chemistry Centre of the University of Minho, Portugal. His work focusses on the development of magnetic materials for sensors and actuators as well as on the synthesis and application of advanced materials for energy storage systems.

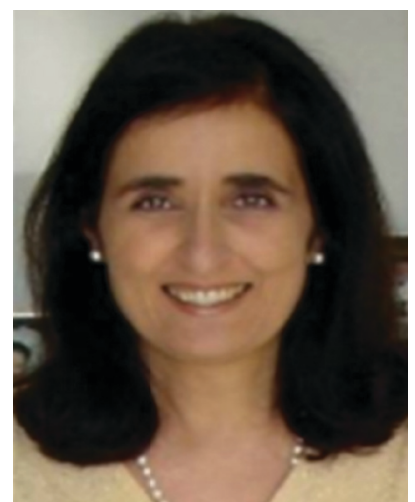

Verónica de Zea Bermudez

V. de Zea Bermudez is Full Professor at the Department of Chemistry of the University of Trás-os-Montes e Alto Douro (UTAD). Her main research interests include organic/ inorganic hybrid materials, solgel chemistry, self-assembly, and self-organization. She is also interested in bioinspired silkand polysaccharide-based biomaterials/biohybrids, and functionalized carbon/silicon dots. Applications envisaged for electrodes, anode and cathode material for energy storage applications, including lithium-ion batteries and printed batteries.

these materials range from batteries, fuel cells, smart electrochromic/thermotropic windows, and solar concentrators, to bone regeneration, drug delivery and superhydrophobic coatings. 
This is the reason why electrolyte solutions must be compulsory present in the system.

The combination of liquid electrolytes with separators is the source of several critical issues that need to be addressed. The most common used electrolytes are composed of lithium salts dissolved in organic carbonates, ${ }^{14}$ which are flammable, increasing the risk of explosion or combustion of the battery. Moreover, they present significant levels of toxicity and are dangerous to the environment. Consequently, robust battery casing is mandatory to prevent electrolyte leakages. Finally, the application of liquid components in batteries reduces their lifetime, as the electrolytes easily degrade the battery components. ${ }^{15}$ The aforementioned shortcomings led to the idea of removing the liquid electrolyte and increasing the ionic conductivity of separator membrane so that the later component acts simultaneously as separator and electrolyte, a step forward in the SSB approach. ${ }^{16}$

SSBs have a constitution and working principle similar to the common LIBs (Fig. 1). The main difference lies on the constitution of the separation between the electrodes, that instead of the typical separator/electrolyte system, is based on a solid electrolyte. As stated above, this electrolyte must be an electronic insulator and ionic conductor. ${ }^{17}$ The conduction mechanism in this system is based on chemical and electrochemical potential gradients. ${ }^{18}$ Theoretically, SSBs present several advantages over common batteries, as they are lighter, smaller, and can provide higher energy outputs, with improved efficiency and low self-discharge. ${ }^{19}$ The development of the SSB technology accompanied that of common batteries throughout history, with the first solid electrolyte materials being developed in the 1950 decade. ${ }^{20}$ However, since them several limitations held back the expansion and extensive commercialization of this technology due to their lower ionic conductivity, difficult interfacial contact, uneven current density distribution and thermal expansion of the components. ${ }^{21}$

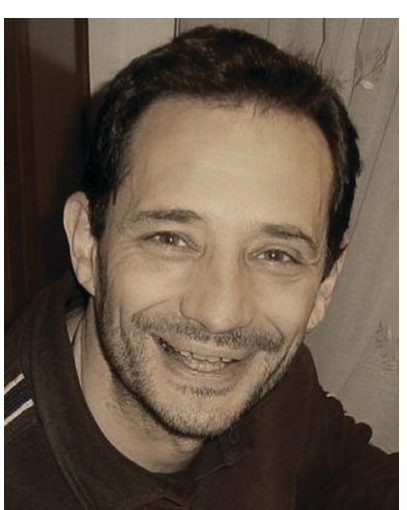

Senentxu Lanceros-Méndez
S. Lanceros-Mendez is Ikerbasque Professor and Scientific Director at the BCMaterials, Basque Center for Materials, Applications and Nanostructures, Leioa, Spain. He graduated in physics at the University of the Basque Country, Leioa, Spain and obtained his PhD degree at the Institute of Physics of the Julius-Maximilians-Universität Würzburg, Germany. He is also Associate Professor at the Physics Department of the University of

Minho, Portugal (on leave) and from 2012 to 2014 he was also Associate Researcher at the INL - International Iberian Nanotechnology Laboratory. His work is focused in the area of smart and multifunctional materials for sensors and actuators, energy and biomedical applications.

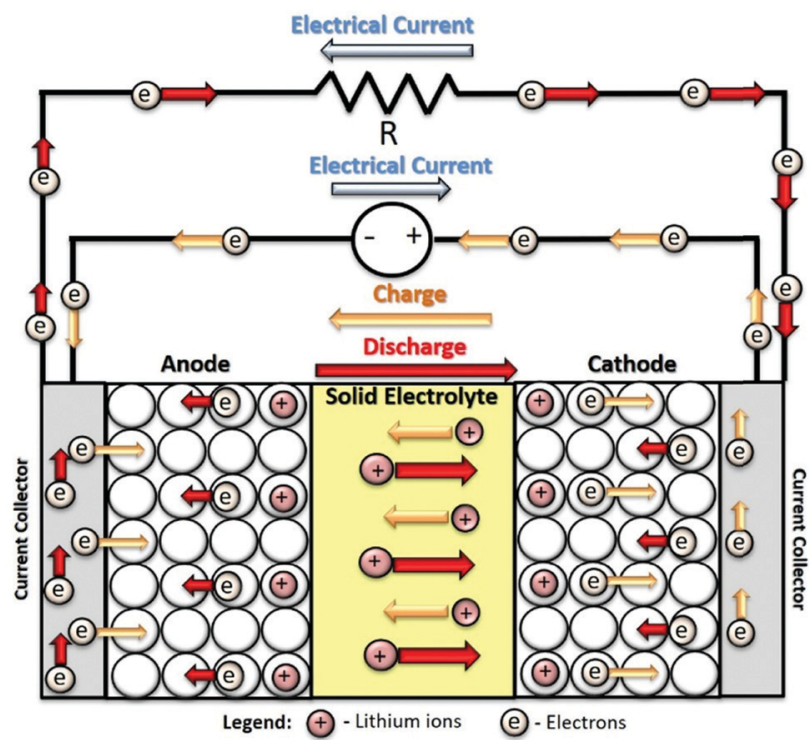

Fig. 1 Schematic representation of the composition and charge/ discharge process of an archetypal LIB.

SSBs can comprise two types of separators: inorganic electrolytes and solid polymer electrolytes (SPEs). ${ }^{22}$ Inorganic electrolytes are usually composed of ceramic crystalline materials, such as lithium super ionic conductor (LISICON), ${ }^{23}$ sodium ( $\left.\mathrm{Na}\right)$ super ionic conductor (NASICON), ${ }^{24}$ perovskites $^{25}$ or garnets, ${ }^{26}$ and possess high ionic conductivity, high electrochemical window, and good thermal stability. However, there are significant issues in the interfacial contact with the electrodes and a higher risk of lithium dendrite growth, as well as difficulties when it comes to production at large scale ${ }^{18}$ In this context new approaches as the use of three component SPEs are being applied in this field. Particularly, the application of microporous materials, such as metal-organic frameworks (MOFs) and zeolites, has been the subject of interesting studies, taking advantage of the high surface area and tunable pore size of those materials, demonstrating their suitability for SPE development. SPEs are discussed in detail in the next section.

\section{Solid polymer electrolytes}

Solid polymer electrolytes (SPEs) can be defined as "solvent-free salt solutions in a polymer host material that shows sufficient mechanical stability to be considered solid in a macroscopic sense". ${ }^{27}$ These materials are essential in the operation of SSBs.

The main advances in the development of SPEs and SSBs on the last 50 years are summarized in Fig. 2. The first SSBs were developed in the 1950s and were based in silver (Ag) and lead $(\mathrm{Pb}) .{ }^{20}$ Their first application in LIBs appeared later in $1979 .^{28}$ Several materials such as NASICON, ${ }^{29}$ lithium phosphorus oxynitride (LIPON) ${ }^{30}$ or lithium lanthanum titanate (LLTO) ${ }^{31}$ were developed in this period. In particular, the development of SPEs started in 1973 with the discovery of the complexation of alkali metal salts, dissolved in poly(ethylene oxide) (PEO), that formed high conductive complexes. ${ }^{32}$ A similar approach was 


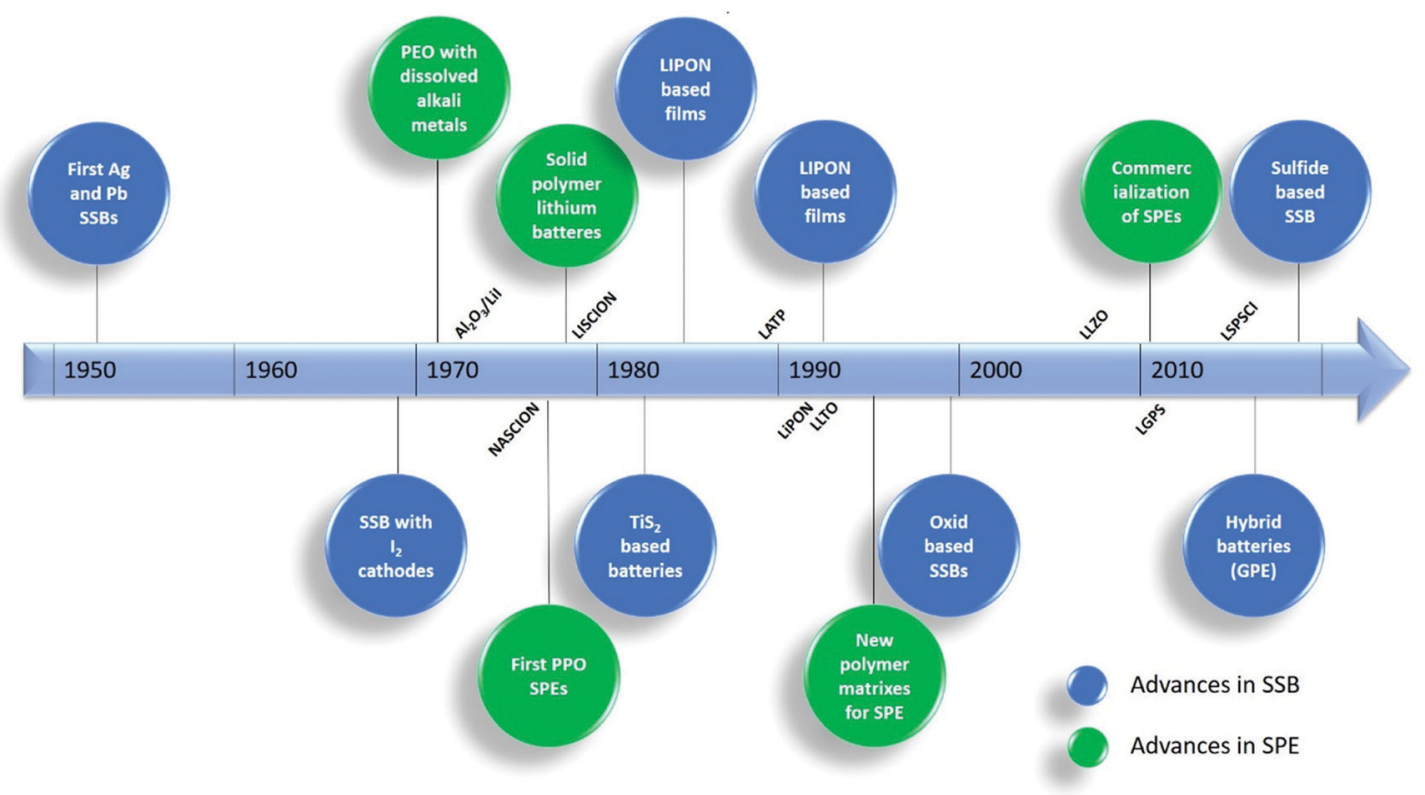

Fig. 2 Chronologic line and main milestones in the development of SSBs. Adapted from ref. 39

taken later, in 1978, using PPO as polymer matrix. ${ }^{33}$ Other polymer matrixes, such as poly(acrylonitrile) $(\mathrm{PAN})^{34}$ or PVDF ${ }^{35}$ were applied in the following years, particularly for use in lithium metal batteries. The efforts to increase the ionic conductivity of SPEs extended to the 1980 and 1990 decades, mainly with the introduction of different kinds of nanoparticles and superionic conductors within the polymer matrix. ${ }^{36}$

The interest in the functionalization of SPEs has increased in recent years, due to the quick expansion of the electric mobility concept and the widespread use of LIBs, which raised concerns with respect to security and environmental issues. ${ }^{37}$

The performance of a SPE in a LIB is affected by different parameters, which must be tuned in order to produce a functional device. The most critical parameters are those directly related with the ion conduction, in particular ionic conductivity, interfacial compatibility, and lithium-ion transference number. Then, stability parameters, such as thermal or mechanical, also play a major role, as they allow the operation in a wider range of conditions. Finally, there are other parameters that are not essential for the operation of the SPE, but are recommendable for environment, health and safety reasons (Fig. 3). Specifically, the requirements to be fulfilled by a SPE are high ionic conductivity (above $10^{-4} \mathrm{~S} \mathrm{~cm}^{-1}$ ) at room temperature, lithium transference number close to unit, wide electrochemical stability window (up to $5 \mathrm{~V}$ ), high thermal and mechanical stability, compatibility with the electrode materials, non-volatility, low toxicity, and low environmental impacts, either in the synthesis, use, and end of life stages. To find the perfect balance between all these properties is a challenge that must be overcome in the next years. ${ }^{38}$

\section{Advantages and disadvantages}

SPEs present several advantages over the most commonly used liquid electrolytes. The most important one is safety, mainly

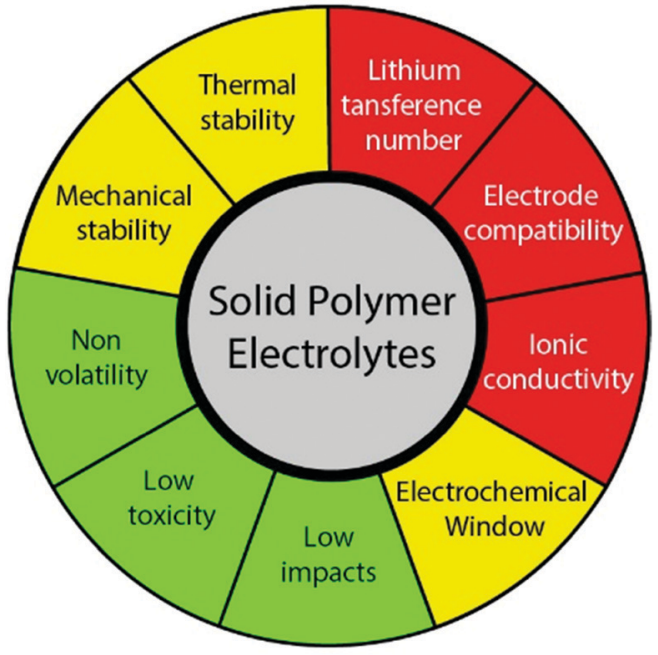

Fig. 3 Main parameters that affect the performance of a SPE: critical (red), important (yellow) and recommendable (green).

due to the low flammability of the solid material when compared to liquid components, as illustrated in Fig. 4. By avoiding the use of liquid components, the need to apply strong encapsulating materials to the batteries is suppressed, as liquid electrolyte leakage no longer exists. ${ }^{40}$ The high mechanical and thermal stability of SPEs allows the battery accommodating more charge/ discharge cycles in a wide range of temperatures. ${ }^{41}$ The use of polymers is beneficial, as they improve the resistance to the variation of volume in the electrodes. ${ }^{42}$ The immobility of the SPE anionic framework allows higher power capabilities, leading to faster charging of the batteries without compromising their structural integrity. ${ }^{43}$ Altogether, the use of SPEs instead of common liquid electrolytes is advantageous in terms of safety, stability and durability of LIBs. 

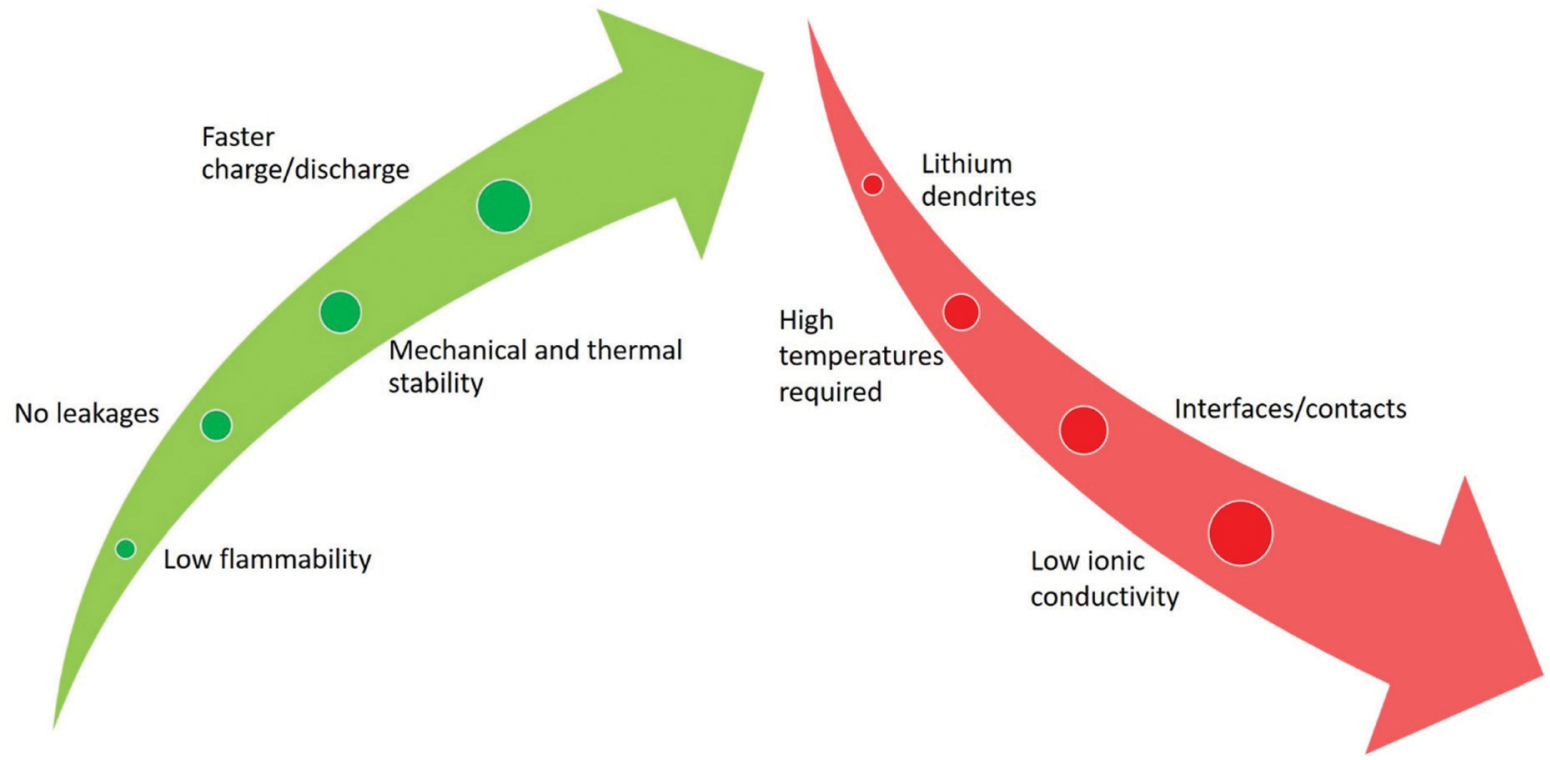

Fig. 4 Advantages (green color) and disadvantages (red color) of SPEs compared with conventional liquid electrolytes for LIB applications.

The main drawback regarding the application of SPEs is their low room temperature ionic conductivity, which is caused by the poor diffusion of ions in the solid matrix when compared to conventional liquid electrolytes. This issue limits SPE operation to higher temperatures, in which the mobility is increased. ${ }^{44}$ Another disadvantage of SPEs is that the interface between the electrodes and the SPE is often modified due to interfacial reactions between both components, leading to higher ionic resistance in the battery and therefore lower performances are achieved. In addition SPEs are subjected to mechanical stresses during electrochemical cycling, which can affect their structural integrity, due to the development of cracks in their structure. ${ }^{45}$ Another trouble that derives from the absence of liquid components is that the contact between the SPE and the electrodes is difficult due to the volume changes, increasing the resistance of the battery. ${ }^{46}$ Finally, the lithium dendrite growth phenomenon is considered a major concern, particularly at high discharge rates, which can

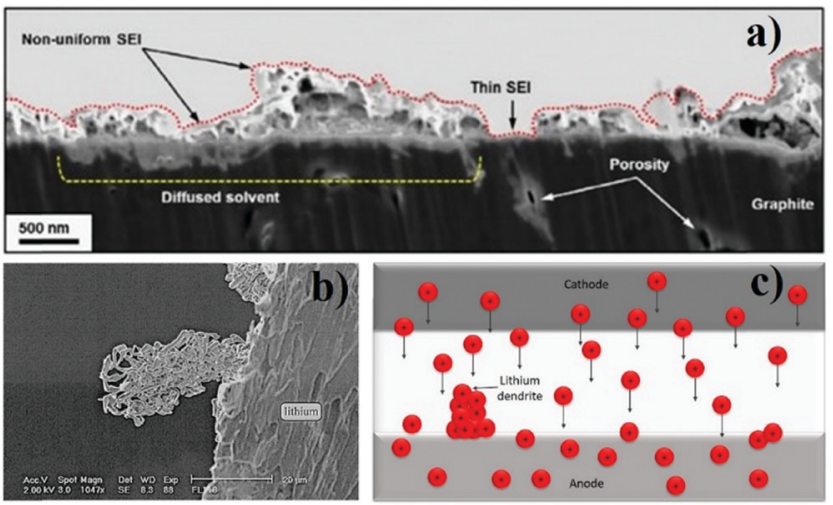

Fig. 5 Scanning electron microscopy (SEM) image of the SEI layer in a LIB anode $^{54}$ (a) SEM image of a lithium dendrite ${ }^{55}$ (b); schematic representation of the lithium dendrite formation process (c). cause loss of battery performance, or even short circuits. ${ }^{47}$ Despite the above limitations, it is expected that in future years the advances in research will bring valuable solutions, turning the SPEs in a more effective option to application in LIBs instead of the conventional liquid electrolytes.

\section{Electrode/electrolyte interface}

One of the most critical issues regarding SPEs is the interface between the electrolyte and the electrodes. In common LIBs this interface is facilitated because of, not only the presence of a liquid component that allows wetting of the electrodes, but also the formation of a passivation layer (usually known as solid electrolyte interphase (SEI)) on the electrodes' surface (Fig. 5a). This layer results from the decomposition of the electrolyte during battery operation and prevents further degradation of other battery components. ${ }^{48}$ However, the SEI increases the internal resistance of the battery, which limits the charge/ discharge process, particularly at high rates. ${ }^{49,50}$

In the anode/SPE interface, the main problem is lithium dendrite growth (Fig. 5b), particularly when the anode is composed of metallic lithium. The lithium dendrites are rigid tree-like structures that are produced due to the incorrect deposition of lithium ions on the electrode's structure (Fig. 5c). The dendrites grow throughout the solid electrolyte, particularly when metallic lithium is used as anode, leading to loss of battery performance as the number of available lithium ions decreases. In extreme cases lithium dendrites can pierce the solid electrolyte and cause short circuit in the battery. ${ }^{51}$ This phenomenon induced the creation of SPEs with uniform lithium-ion transportation pathways enabling uniform deposition of the charges. ${ }^{52,53}$ Another situation that may occur in the anode is related to the volume changes during the charge/discharge process which cause contact loss between this electrode and the SPE, increasing the impedance. ${ }^{46}$ 
In the case of the cathode, the interfacial issues are similar to those occurring in the anode, although they are more complex, due to the composition of cathode, which gives rise to various solid-solid interfaces between different particles. To address the latter problem, the formation of stable ionconducting networks in the cathode is advisable. ${ }^{56}$

\section{Conduction and diffusion mechanisms}

The study of the conduction and diffusion mechanisms in a SPE plays a key role in the development of the field, as it allows getting a better insight into the behavior of the charges in the SPE structure and helping to decide what can be done to increase the ionic conductivity of the material.

The ionic conductivity is an important property of SPEs, as it represents the ability of the material to allow the ion flux through it, which is the basis of battery operation. However, the ionic conductivity of SPEs is lower than that of liquid electrolytes. $^{46}$ For a battery to work properly, the minimum room temperature ionic conductivity of the SPE must be higher than $10^{-3} \mathrm{~S} \mathrm{~cm}^{-1} .^{57}$

The ionic conductivity $(\sigma)$ of a SPE can be described by eqn (1): ${ }^{58}$

$$
\sigma=F \sum n_{i} q_{i} \mu_{i}
$$

where $F$ is the Faraday constant, and $n_{i}, q_{i}$, and $\mu_{i}$ are the number, charge and mobility of the free ions, respectively. This means that, in order to increase the ionic conductivity of the SPE, one or more of these parameters must be increased.

The ionic conductivity of a material is also strongly dependent of temperature. The Arrhenius model describes this behavior, as described by eqn (2):

$$
\sigma=\sigma_{0} \exp \frac{-E_{\mathrm{a}}}{R T}
$$

where $\sigma_{0}$ is a pre-exponential factor, $E_{\mathrm{a}}$ is the activation energy, $R$ is the gas constant, and $T$ is the temperature. This model explains why the ionic conductivity of a material increases with increasing temperature, due to the improved mobility of the charges, which is related to the rise in the total energy of the system.

Another alternative to describe the conduction mechanisms in SPE is the Vogel-Tamman-Fulcher (VTF) theory. This model is based on the effect of the ion jump motion and polymer chain relaxation and/or segmental motion in the conductivity, which means that there is nonlinearity in the $1 / T$ curve. $^{59}$ This model can be described by the eqn (3):

$$
\sigma=\sigma_{0} T^{-\frac{1}{2}} \exp \left(-\frac{B}{T-T_{0}}\right)
$$

where $B$ is an action factor, related to the activation energy distribution and $T_{0}$ is the reference temperature, usually 10-50 $\mathrm{K}$ below the glass transition temperature. At room temperature, the conductivity can be improved with low glass transition temperature polymers, as just the effect of the polymer segment is considered. ${ }^{60}$

The migration of ions in a polymer matrix under the application of an electric field relies mainly on the formation and dissociation of coordination bonds during the motion of

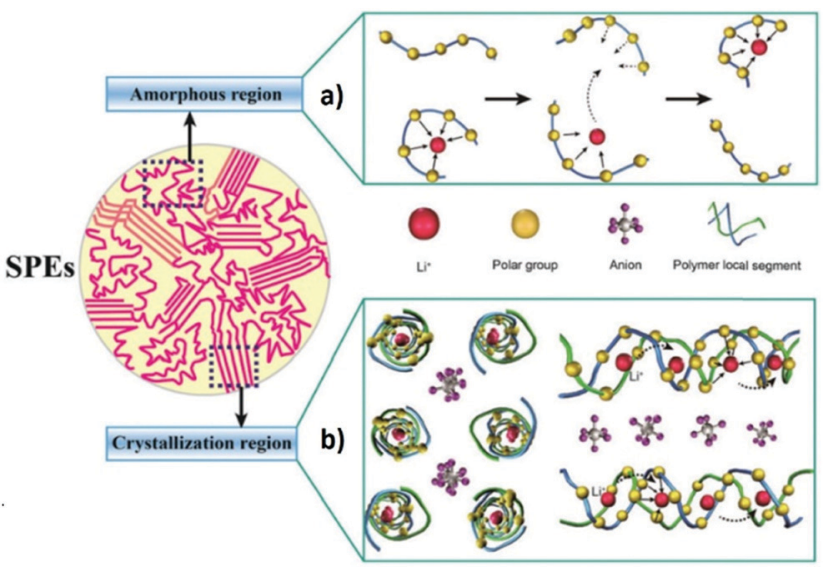

Fig. 6 Schematic illustration of conduction mechanisms in amorphous (a) and crystalline (b) SPEs. ${ }^{66}$

polymer chains (Fig. 6a). ${ }^{61}$ This motion occurs mainly in the amorphous phase of the polymer matrix, meaning that a high crystallinity degree will affect negatively the ionic conductivity of the SPE, due to the higher energy barrier for the movement of the $\mathrm{Li}^{+}$between the preferred sites. Typically, the addition of conductive salts contributes to increase the glass transition temperature $\left(T_{\mathrm{g}}\right)$ value of the polymer due to the slowing down of the segmental dynamics. ${ }^{62}$ The mechanism of the lithium motion on the polymer matrix can be described by the free volume model. Above $T_{\mathrm{g}}$, a state of local segmental motion on the polymer chains occur, which increases the free volume near the moving chain segments. ${ }^{63}$ This volume allows for the intermolecular coordination of the lithium ions, leading to the possibility of changing between coordination sites, in the presence of an electric field. This interchanging between polymer chains is possible due to the reduced energy barrier. ${ }^{64}$ However, Bruce and co-workers introduced a different conduction mechanism based on the movement of lithium ions on the spiral-shaped channels found within the ordered structure of the polymer matrix (Fig. 6b). ${ }^{65}$

Several additives allow to decrease the degree of crystallinity of the polymer, leading to an increase on the mobility of the polymer chains and consequently on the mobility of the charges: ceramic fillers, ${ }^{67}$ MOFs, ${ }^{68}$ ionic liquids (ILs), ${ }^{69}$ and lithium salts. ${ }^{70}$ The addition of the later compounds represents the most efficient way to increase the ionic conductivity of a SPE, by also introducing more places to dissolve lithium ions by complexing them in its structure. Also, the lattice energy of the salt must be low, and the dielectric constant of the polymer must be high to allow the dissociation of the salt in the polymer host. ${ }^{71}$ Finally, for a significant effect on the increase of the ionic conductivity, large amounts of salts are needed, which could also affect other properties of the SPE, namely the mechanical stability, potentially leading to negative effects on the overall performance. ${ }^{72}$

\section{Types of polymer matrix and fillers}

A composite solid electrolyte is typically composed of a host polymer matrix that warrants the structural integrity of the 
electrolyte, and different kinds of fillers. Each filler affects the properties of the electrolyte in different ways, and it is the combination of the polymer matrix with one or more fillers that leads to the electrolyte distinct final characteristics, performance and stability. As stated above, in a SPE the polymer is the constituent that warrants the structural integrity. Thus, it is important that the selected polymer exhibits high mechanical, thermal and electrochemical stability. Traditionally the most widely used polymers belong to the class of thermoplastics, that meet the requirements referred previously. ${ }^{73}$ The main limitation of these polymers is their ionic conductivity, which is generally low $\left(<10^{-5} \mathrm{~S} \mathrm{~cm}^{-1}\right)$ at room temperature, making them a less attractive option for battery applications. The most studied polymer for application in SPEs is PEO, because of its high lithium ion conductivity, especially at high temperatures, when lithium salts are introduced in a composite form. ${ }^{74}$ Other polymers, such as $\mathrm{PVDF}^{75}$ and its co-polymers, ${ }^{76}$ (PAN), ${ }^{77}$ poly(ethylene carbonate) $(\mathrm{PEC})^{78}$ and poly(ethylene glycol) (PEG), ${ }^{79}$ have been also studied and tested. Some works have focused on blends with two or more polymers, in order to combine the best properties of the individual ones. Blends of poly(vinyl chloride) (PVC)/PVDF, ${ }^{80}$ PEO/PMMA ${ }^{81}$ and PVDF-hexafluoropropylene (HFP)/ poly(aniline) (PANI), ${ }^{82}$ are some examples of successfully prepared SPEs. A green approach has gained increasing attention in recent years, in the search for more sustainable alternatives to conventional polymers. In this field, natural polymers are valid options due to their biodegradability and low environmental impact. Studies with polysaccharides, such as cellulose, ${ }^{83}$ pectin, ${ }^{84}$ chitosan $^{85}$ and carrageenan, ${ }^{86}$ have been successfully carried out.

As mentioned above, the incorporation of fillers is essential in the functionalization of a SPE, because these components enhance the properties of the electrolyte, particularly its ionic conductivity and mechanical stability. Fillers can be divided into two categories. The active fillers are able to directly increase the ionic conductivity of the SPE, while the passive fillers exert their influence on other parameters of the SPE, inducing the increase of the thermal or mechanical stability, or reducing the degree of crystallinity, which indirectly facilitates the ion transport. ${ }^{87}$ These fillers include ceramics (barium titanate $\left(\mathrm{BaTiO}_{3}\right),{ }^{88}$ alumina $\left(\mathrm{Al}_{2} \mathrm{O}_{3}\right),{ }^{89}$ silica $\left(\mathrm{SiO}_{2}\right),{ }^{90}$ titania $\left(\mathrm{TiO}_{2}\right)^{91}$ ), carbonaceous (graphene oxide, ${ }^{92}$ carbon nanotubes ${ }^{93}$ ), lithium salts (lithium tetrafluoroborate $\left(\mathrm{LiBF}_{4}\right),{ }^{94}$ lithium hexafluorophosphate $\left(\mathrm{LiPF}_{6}\right),{ }^{95}$ lithium perchlorate $\left(\mathrm{LiClO}_{4}\right),{ }^{96}$ lithium bis(trifluoromethylsulfonyl)imide (LiTFSI) ${ }^{97}$ ), ILs (1-ethyl-3-methylimidazolium bis(trifluoromethylsulfonyl) imide ([EMIM][TFSI]), ${ }^{98}$ and 1-butyl-3-methylimidazolium chloride $([\mathrm{BMIM}][\mathrm{Cl}])^{99}$ ) or microporous materials (zeolites, ${ }^{100}$ nanoclays, ${ }^{101}$ and $\mathrm{MOFs}^{102}$ ).

In particular, microporous materials are attracting increasing interest in recent years for this application, as their properties, such as their tunable micropore structure, high surface area and capacity to encapsulate other components, show potential to overcome several limitations of the actual SPEs. Nonetheless, they have not been intensively studied yet.

\section{Why microporous materials?}

Due to their characteristics and properties, composite solid electrolytes aim to replace the conventional separators and liquid electrolytes employed nowadays in the field of energy storage systems. However, critical issues, such as low ionic conductivity and high interfacial resistance must be addressed in order to make them fully functional and achieve performances similar to the conventional materials. To solve these drawbacks, different approaches have been adopted in recent years, particularly with respect to the used materials and processing techniques.

Microporous materials, such as MOFs and zeolites, are interesting candidates for application in composite solid electrolytes owing to their unique properties. Their crystalline structure with controllable parameters, such as pore size and shape, allows building a network of ion pathways with high ionic conductivity. ${ }^{103}$

Some hollow microporous structures are able to store several lithium ions in their structure, further enhancing ionic conductivity $^{104}$ and lithium transference number. ${ }^{105}$ Other materials can be combined with different metal salts, with the same purpose. ${ }^{106}$ The improvement of the ion conduction properties of the SPE is frequently accompanied by a loss of mechanical properties of the SPE, particularly with the use of ceramic conductive materials. This effect can be overcome by the implementation of microporous materials, that are able to retain those mechanical properties. ${ }^{107}$ Further, the high surface area of microporous materials offer a higher number of contact points, which facilitates the interfacial compatibility between the SPE and the electrodes. ${ }^{108}$ Fig. 7 presents the main modification strategies used to improve different properties of microporous materials, in order to make them suitable for applications in SPEs. These strategies include microstructure tunning, ${ }^{109}$ modification of ligands, ${ }^{110}$ addition of functional groups, ${ }^{111}$ surface modification and hybridization of the microporous species with other materials. ${ }^{108}$

In parallel, these materials can be used to encapsulate/adsorb other materials, such as lithium salts or ionic liquids (ILs), to further facilitate the conduction mechanism in the composite solid electrolytes. This three-component approach (one polymer and two complementary fillers) enables the synthesis of more stable and improved solid electrolytes, in which one filler leads to the enhancement of the mechanical or thermal properties, whereas the other promotes the enhancement of ionic conductivity, leading to a reduction of the needed quantity of each one for the electrolyte to perform properly. ${ }^{112}$ The use of microporous fillers for this strategy is advantageous when compared with the more common ones based on ceramic conductors which are not able to be combined with other fillers in the same way as microporous materials, due to the lack of a suitable structure to combine with a complementary filler. Further, the high surface area of the microporous materials allows for a higher number of interaction sites which stabilizes the interfacial contact with the electrodes. ${ }^{113}$

The main difference between zeolites and MOFs is the nature of their structures. While zeolites are entirely inorganic, 


\section{Modification strategies of microporous materials}
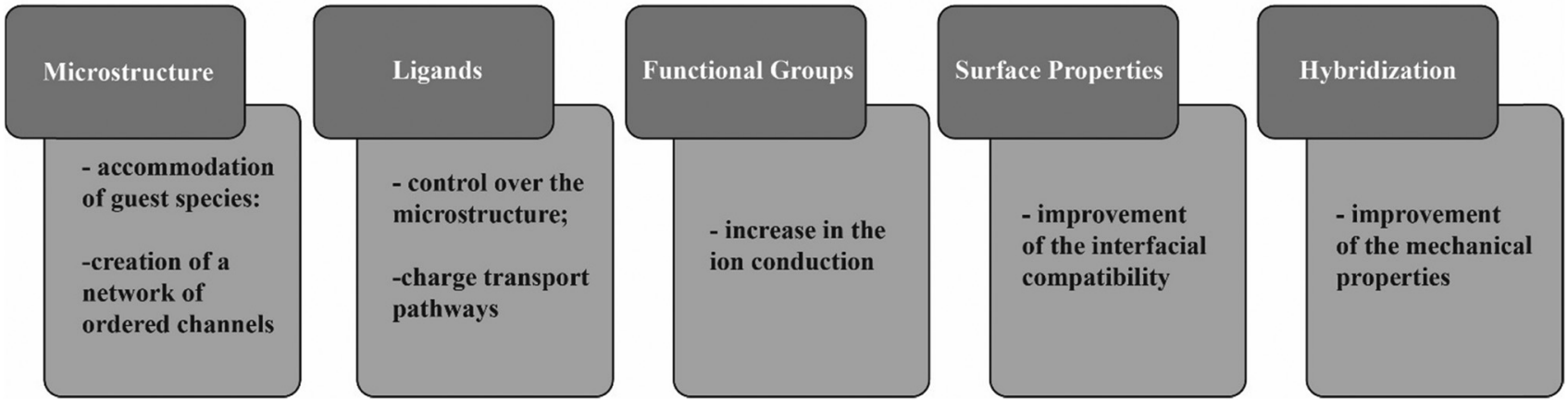

Fig. 7 Schematic representation of the main modification strategies of microporous materials and their effect in properties relevant for solid electrolytes.

MOFs present an inorganic-organic hybrid structure with large pore sizes and volumes.

Moreover, zeolites can be found in nature and synthetic structures are mostly mimicked from the natural structures. In contrast, MOFs are exclusively synthetic, allowing the production of a significantly higher number of possible structures, meaning that they are more versatile and adaptable. ${ }^{114}$ However, zeolites exhibit higher thermal and chemical stabilities, longer lifetimes, and cheaper production costs, being also an environmentally friendlier option (Fig. 8). ${ }^{115}$

The most extensively used techniques for the production of composite solid electrolytes are solvent casting and hot pressing. Hot pressing is considered the simplest and cheapest process and has the advantage of being completely solvent-free. ${ }^{116}$ However, printing techniques attracted considerable interest in recent years, due to the possibility of tackling the interfacial resistance problems, among others. ${ }^{117}$ Printing techniques allow the deposition of the different battery components layer by layer, leading to the manufacturing of hybrid interfaces that are, neither electrode, nor electrolyte, but a mix of both. ${ }^{118}$ These interfaces can suppress the issue of high resistance, because the

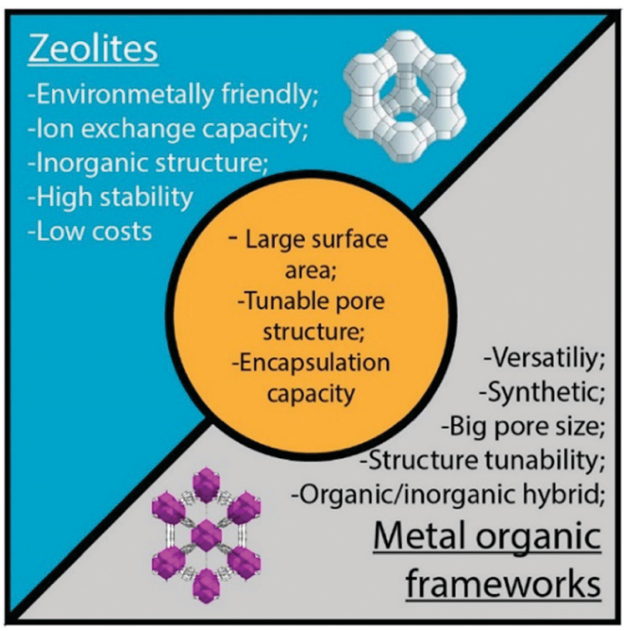

Fig. 8 Main characteristics and common properties of zeolites and MOFs. battery is built as a single device, and not by the assembly of different components.

\section{State of art on microporous materials for polymer based composite solid electrolytes}

According to the International Union of Pure and Applied Chemistry (IUPAC), porous materials can be classified in three different categories. Microporous materials are characterized by pore sizes smaller than $2 \mathrm{~nm}$; mesoporous materials show pore sizes between 2 and $50 \mathrm{~nm}$; and macroporous materials show pore sizes larger than $50 \mathrm{~nm} .^{119}$

Microporous materials are particularly appealing for energy storage applications due to their good thermal stability ${ }^{120}$ and high surface areas, that offer a higher number of sites for interfacial reactions. Further, the adjustable pore sizes and shapes provide the ideal space to encapsulate other components in their structure. Finally these materials are known to possess nanoscale effects, both in their channel structure and in their pore walls, resulting in enhanced mechanical, electrical, and optical properties. ${ }^{111}$ There are different kinds of microporous materials, such as aluminosilicates, metal oxides, nanoclays, molecular sieves, zeolites, and MOFs. ${ }^{111}$ As previously mentioned, microporous materials have particular interest in the SPE field, as they are able to encapsulate other materials in their structure. In the light of this three-component approach, the microporous material works as a host for the other filler, improving the mechanical and thermal properties of the SPE, while the second filler enhances the ionic conductivity. ${ }^{112}$ This approach allows an increase in the quantity of filler that is possible to use without compromising the overall performance of the composite solid electrolytes in terms of mechanical or thermal properties. ${ }^{121}$

\section{Metal-organic frameworks}

Metal-organic frameworks, MOFs, can be defined as crystalline porous solids composed of a three-dimensional (3D) network of 
metal ions held in place by multidentate organic molecules. ${ }^{122}$ The first MOF, inspired in the characteristics of zeolites, was reported in 1995, using 1,3,5-benzenetricarboxylate as building block. ${ }^{123}$ This field grew strongly since then, with successive studies and synthesis of new structures. There are almost 70000 different MOFs reported nowadays. ${ }^{124}$

MOFs present a variety of interesting properties, combining high porosity with large pore size and volume, outstanding surface area (up to the record of $7000 \mathrm{~m}^{2} \mathrm{~g}^{-1}$ for the NU-110E $\mathrm{MOF}^{128}$ ), possibility to encapsulate or adsorb other materials in their structure, and fast electrochemical kinetics. MOFs have been used in a wide range of applications, including gas storage and separation, ${ }^{129,130}$ drug delivery, ${ }^{131}$ catalysis, ${ }^{132}$ and chemical sensing. ${ }^{133}$ The possibility to control the pore size, shape and surface physical-chemical characteristics, leads to the synthesis of structures with tailored properties for specific applications, increasing the interest of these materials in the energy area in recent years. ${ }^{125,134}$

The main advantages of the application of MOFs in SPEs are: (1) their 3D and easily tunable pore structures (Fig. 9) that offer many contact points between the electrolyte and the electrode active material at an atomic level; (2) their adequate electrochemical window; and (3) their good thermal and mechanical properties. $^{135}$ Furthermore, the ability to control the surface polarity of the MOFs allows the optimization of their
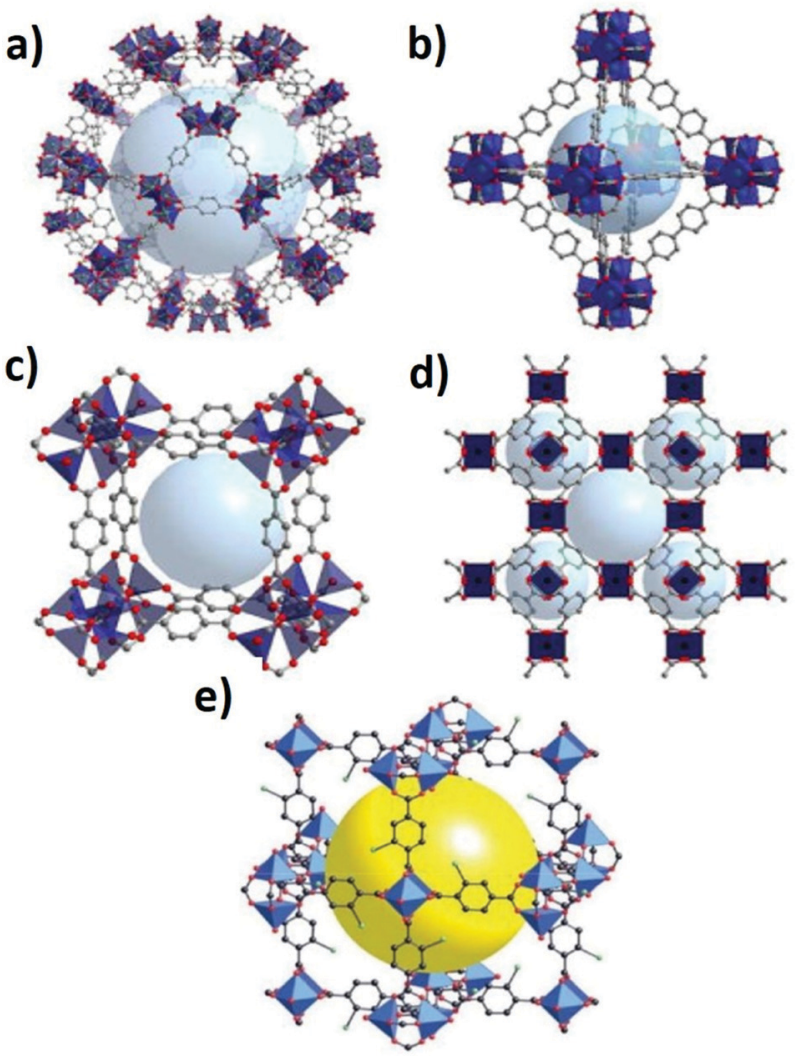

Fig. 9 Typical structure of representative MOFs: MIL-101 (a), UIO-67 (b) MOF-5 (c), HKUST-1 (d) ${ }^{125}$ and MOF-101 (e). ${ }^{126,127}$ electrochemical properties through the modulation of the interfacial interactions. ${ }^{108}$

These characteristics led to a growing interest in the application of MOFs in composite solid electrolytes, due to the possibility of a more efficient transport of the lithium ions through the ordered channels in the MOFs structure. ${ }^{108}$ Table 1 presents the work developed in recent years regarding the application of different MOFs as fillers in composite solid electrolytes.

The most extensively used approach in the production of composite solid electrolytes with MOFs is the addition of the MOF to a polymer matrix (e.g., PEO) including a lithium salt (e.g., LiTFSI). Studies with the PEO host matrix have been carried out using different MOFs, with promising results. The addition of aluminum (Al)-MOF nanorods altered the properties of the matrix due to the strong interfacial interactions with the polymer chains, increasing the ionic conductivity and lithium transference number of the SPE when compared with pure $\mathrm{PEO}$, and enlarging in parallel the electrochemical window up to $4.7 \mathrm{~V}^{140}$ The use of $\mathrm{Zn}_{4} \mathrm{O}(1,4$-benzenedicarboxylate) (MOF-5) proved to stabilize the resistance in the interfaces of the tested cells and increased the cycling stability of the batteries up to 100 cycles. ${ }^{144}$ This MOF is also able to significantly increase the lithium transference number and ionic conductivity of a TFEMA/PEGMA blend, due to the increase in the amorphous phase content and the microphase separation morphology caused by the addition of the MOF. ${ }^{138}$ A comparison between magnesium (Mg)-TPA and Mg-TMA MOFs fillers in a PEO/LiTFSI matrix was performed. The addition of the MOFs promoted a reduction of the degree of crystallinity, further improving the conduction mechanism and increasing the ionic conductivity (Fig. 10a). ${ }^{145}$ Copper $(\mathrm{Cu})$-BDC MOFs promoted the thermal stability of the composite solid electrolyte, allowing the battery operation at high temperatures with reduced risks. ${ }^{150}$ The characteristics of the $\mathrm{Ni}_{3}$-(BTC) $)_{2}$ MOF proved to enhance the interfacial properties of the SPE, leading to better cycling performances, and to the suppression of lithium dendrites, without compromising the internal resistance of the cell (Fig. 10b). ${ }^{151}$ The MIL-35(Al) showed exceptional battery performance at high discharge rates, due to its ability to dissolve lithium salts, increasing the ionic conductivity. ${ }^{152}$

MOFs as UiO-66 have the ability to encapsulate liquid electrolytes in their nanostructure to form efficient ion conductors. These compounds increase the compatibility between the electrode and the separator, leading to higher performance batteries. ${ }^{148}$ Ion exchange techniques have been used in UiO-66- $\mathrm{NH}_{2}$ MOFs to insert lithium salts in their structure, creating a single-ion superionic conductor. Then, the prepared MOFs were applied as fillers in a PVDF matrix by solution casting methods. The membranes presented high ionic conductivity at room temperature and an excellent battery capacity retention of $97 \%$ after 500 cycles. ${ }^{102}$ UiO-66- $\mathrm{NH}_{2}$ were functionalized with vinyl groups and applied in a poly(ethylene glycol) diacrylate (PEGDA) matrix using ultraviolet (UV) photopolymerization. The ionic conductivity of the prepared electrolyte was enhanced by about 5 times upon addition of the MOF. 
Table 1 State of the art of the use of MOFs in the formulation of composite solid electrolytes and the corresponding LIB performance

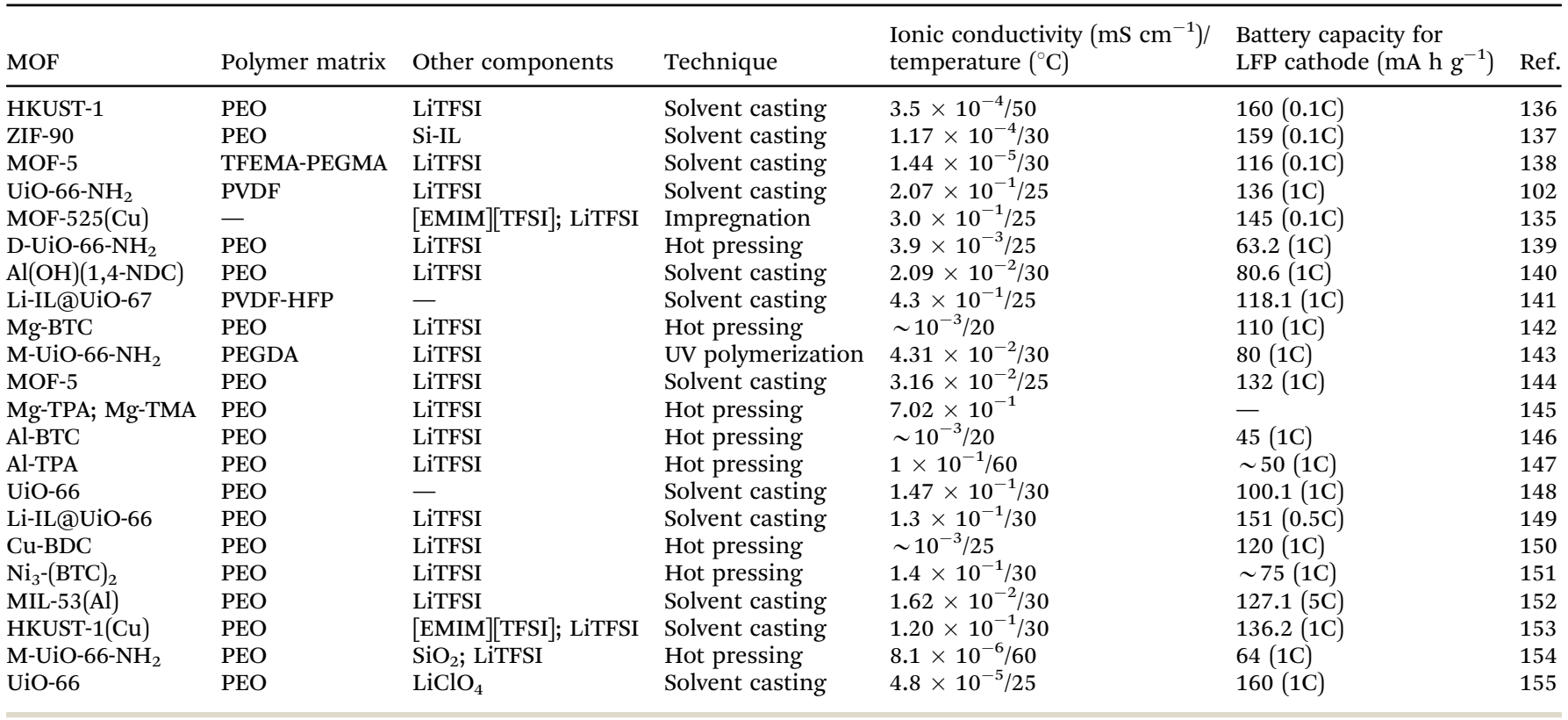

The latter demonstrated an excellent interfacial contact with the electrodes. The assembled battery showed a good performance, particularly at high temperatures. ${ }^{143}$ UiO-66 was also successfully used combined with $\mathrm{LiClO}_{4}$, to form a stable composite solid electrolyte with strong intermolecular interactions, which resulted in a significant increase in the ionic conductivity and excellent battery performance, particularly at high temperatures. ${ }^{155}$ ZIF-90 can be combined with imidazole ionic liquid containing trimethoxysilane groups (Si-IL), leading to strong interaction between the components, which results in good battery performances, particularly at high temperatures. $^{137}$

MOF-525(Cu) was impregnated with a mixture of [EMIM][TFSI] and LiTFSI to form a solid-like electrolyte with high room temperature ionic conductivity and good compatibility with both $\mathrm{LiFePO}_{4}$ and the Li-metal anode, showing low interfacial resistance. The assembled battery was characterized by a good retention capacity in a wide temperature range $\left(-20\right.$ to $\left.150{ }^{\circ} \mathrm{C}\right)$ as shown in Fig. 10c and d. ${ }^{135}$ A similar strategy was applied with the UiO-67 MOF. The prepared MOF was dispersed in a PVDF-HFP matrix, leading to a quasi-solid-state electrolyte, with high ionic conductivity and good cycling stability up to 300 cycles. ${ }^{141}$ The encapsulation of [EMIM][TFSI] and lithium salts within the structure of UiO-66 also led to promising results, with ionic conductivities in the order of $10^{-4} \mathrm{~S} \mathrm{~cm}^{-1}$ at $30{ }^{\circ} \mathrm{C}$ and excellent discharge capacities at high rates. ${ }^{149}$ This method has been also successfully applied with the HKUST-1(Cu) MOF with outstanding room temperature ionic conductivity, due to the formation of a strong ion-conductive network in the polymer matrix. ${ }^{153}$

A cationic MOF was developed from UIO-66 and used as filler in an anion-immobilized polymer electrolyte for lithium dendrite-free batteries. The polymer electrolyte was synthesized by hot pressing. The addition of the cationic MOF increased the ionic conductivity of the polymer matrix and inhibited the formation of lithium dendrites. ${ }^{139}$ The addition of $\mathrm{SiO}_{2}$ to the UIO-66 structure promoted a more uniform diffusion of the lithium through the composite solid electrolyte, and a better interface between the composite solid electrolyte and the electrodes. ${ }^{154}$ Hot pressing was also successfully applied in the synthesis of PEO SPEs using Mg-BTC (Fig. 11a) ${ }^{142}$ and Al-BTC MOFs, ${ }^{146}$ leading to an increase of the ionic conductivity by two orders of magnitude even at low temperatures. Hot pressed PEO/Al-TPA was applied in both lithium-metal and lithium-sulfur batteries, presenting stable performances up to 100 cycles in both studies. ${ }^{147}$ The application of HKUST-1 in a PEO matrix contributed to a better control of the heat release of the SPE, simultaneously enhancing the ionic conductivity and the cycling performance, particularly for a MOF content of $10 \%$ (Fig. 11b). ${ }^{136}$

Covalent-organic frameworks (COFs) are structures similar to MOFs, that instead of the metal-based nodes, possess light elements, such as hydrogen carbon, boron, nitrogen, and oxygen, in their structure, linked by covalent bonds. ${ }^{156}$ COFs share most of their properties with MOFs, namely high surface area, tunable porosity and homogeneously distributed channels. However, due to the absence of metal ions in the COF structure, they tend to be lighter than MOFs. ${ }^{157}$ There are some applications of COFs in the energy storage field, particularly as fillers for battery separators, ${ }^{103}$ but their application in the SPE field is not yet studied in detail, with just a couple of works reported. ${ }^{158,159}$ Thus, there is still a large potential in the application of those materials in SPEs. ${ }^{112}$

\section{Zeolites}

Zeolites are micro or mesoporous structures composed of aluminosilicate minerals linked by oxygen atoms, resulting in a 3D network with pores of molecular size. ${ }^{160}$ Generally, zeolites have the following chemical formula: ${ }^{161}$ 

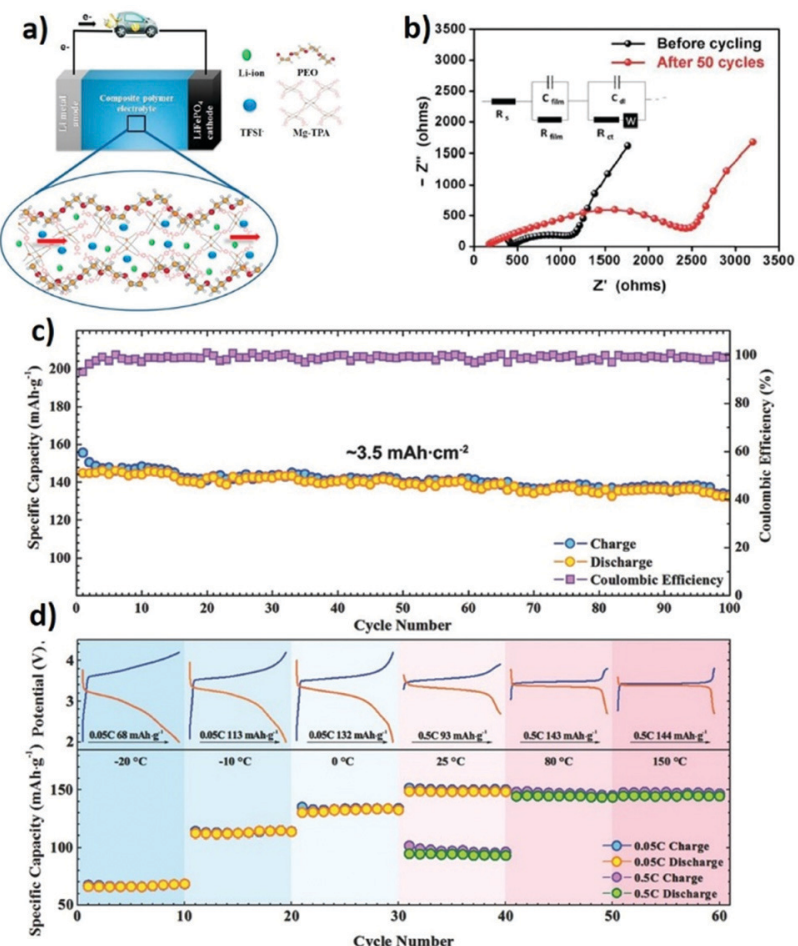

Fig. 10 Schematic representation of the lithium ion migration in the $\mathrm{Mg}$ TPA MOF based composite solid electrolyte $(a)^{145}$ and impedance measurements of $\mathrm{Ni}_{3}$-BTC MOF based composite solid electrolytes before and after cycling, with the corresponding equivalent circuit (b). ${ }^{151}$ (c) Cycling performance and coulombic efficiency of the Li|Li-IL@MOF|LFP SSB at 0.1C charge/ discharge rate at room temperature. (d) Temperature-dependent cyclability of the Li|Li-IL@MOF|LFP SSB with corresponding charge/discharge curves. ${ }^{135}$
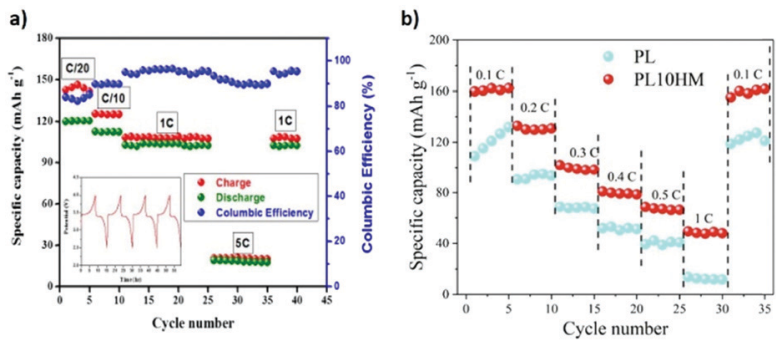

Fig. 11 Rate performance of a $\mathrm{Li} / \mathrm{Mg}-\mathrm{BTC} / \mathrm{LiFePO}_{4}$ hot pressed cell at $70{ }^{\circ} \mathrm{C}$ and corresponding cycling profile ${ }^{142}$ (a); rate performance of the PEO/HKUST-1 SPE at $50{ }^{\circ} \mathrm{C}$ when compared with a PEO SPE (b)..$^{136}$

$$
\mathrm{M}_{x} \mathrm{D}_{y}\left(\mathrm{Al}_{x+2 y} \mathrm{Si}_{n-(x+2 y)} \mathrm{O}_{2 n} m \cdot \mathrm{H}_{2} \mathrm{O}\right)
$$

where $\mathrm{M}$ is a monovalent cation, such as $\mathrm{K}^{+}, \mathrm{Ca}^{+}$or $\mathrm{Na}^{+}$, and D is a divalent cation, such as $\mathrm{Mg}^{2+}, \mathrm{Ca}^{2+}, \mathrm{Sr}^{2+}$ or $\mathrm{Ba}^{2+}$.

The first reported zeolite, stilbite, was discovered by the Swedish mineralogist Cronstedt in $1756 .{ }^{162}$ The characteristic properties of zeolites were described in a couple of works at the end of the XVIII century. The first synthetic zeolites were developed in 1948 by Richard M. Barrer. ${ }^{163,164}$ The field has grown through the years until now, with more than 250 different identified structures.
Zeolites can occur naturally and can be synthesized in laboratory. According to the Zeolite Association Structure Commission, there are 252 different zeolite frameworks reported nowadays, with 47 known to occur in nature. The natural zeolites are divided into 7 families (Analcime, Chabazite, Gismondine, Harmotome, Heulandite, Natrolite and Stilbite) depending on their structure (Fig. 12). ${ }^{165}$ They are mainly applied as catalysts and sorbents. ${ }^{166}$ The most important properties of zeolites are their well-defined pore structure that allows for the selective encapsulation of other materials, their large surface area, which offers more sites for the occurrence of interfacial reactions, their cation exchange capacity that allows the introduction of specific species of interest in the zeolite's structure, and their high thermal stability which allows their operation at high temperatures. ${ }^{161}$

Some interesting applications of zeolites are the production of dyes for microfluidics, ${ }^{167}$ biomass conversion processes, ${ }^{168}$ carbon dioxide $\left(\mathrm{CO}_{2}\right)$ capture and conversion, ${ }^{169,170}$ air pollution remediation, ${ }^{171,172}$ and water purification. ${ }^{173}$ Zeolites are commonly used in energy applications, such as thermal energy storage ${ }^{174}$ and fuel cell technology, both in the fuel production and in the cell operation fields. ${ }^{175,176}$

In the field of the LIBs, zeolites are employed in the anodes, to prevent the volume changes during the charge and discharge processes, and to increase the specific energy of the batteries. ${ }^{177,178}$ Zeolites are also used in the development of nanocomposite separators, with the goal of increasing the wettability and electrolyte uptake of the membranes, as well as to improve their stability at high temperatures. ${ }^{179,180}$ Zeolites, such as $13 \mathrm{X},{ }^{179} \mathrm{ZSM}-5^{180,181}$ and $4 \mathrm{~A},{ }^{182}$ have been used

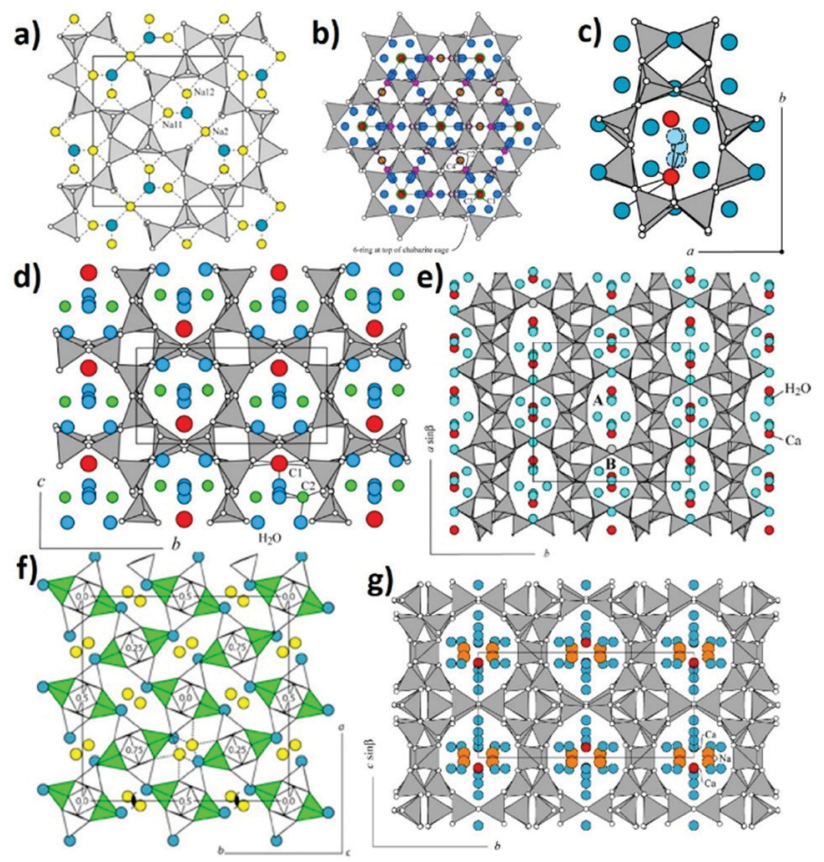

Fig. 12 Typical structure of the natural zeolites analcime (a), chabazite (b), gismondine (c), harmotome (d), heulandite (e), natrolite (f) and stilbite (g). Source: International Zeolite Association. 
with this purpose, due to their interstitial cavities that increased the overall porosity of the separator. Ion exchange techniques were applied in zeolite $\mathrm{H},{ }^{183}$ and $\mathrm{MFI}^{184}$ to improve the conduction characteristics of the separator. However, the use of zeolites in SPEs has not been object of an extensive study yet. The only reported work in this field included the use of a modified high silica SSZ-13 zeolite and LiTFSI fillers in an PEO matrix. The synthesized SPE presented an outstanding ionic conductivity of $5.34 \times 10^{-2} \mathrm{~S} \mathrm{~cm}^{-1}$ at $70{ }^{\circ} \mathrm{C}$, and high battery performance using both $\mathrm{LiFePO}_{4}$ and $\mathrm{LiNiCoAlO}_{2}$ cathodes, with good capacity retention after 80 cycles. ${ }^{185}$ Despite the fact that wettability and electrolyte uptake are not useful properties in the performance of a composite solid electrolyte due to the absence of liquid components, the thermal stability is important to improve the operation of solid-state batteries that usually work at high temperatures. Also, the ion exchange properties and the interstitial cavities can represent advantages both for the introduction of other materials in the zeolite structure and for the development of high ionic conductivity channels in the composite solid electrolyte.

\section{Conclusions}

The development of fully functional SPEs represents a critical step towards the next generation of energy storage systems. This technology will allow, not only producing more durable and efficient devices, but also overcoming the safety problems associated with the liquid components used nowadays. However, there is still a long way to go, until SPEs become a valid option at an industrial scale. This is mainly because of the lack of systematic knowledge and control of the conduction mechanisms and interfacial problems, that severely limit the operation of SPEs to low charge rates and high temperatures. Thus, it is necessary to get a better understanding about these mechanisms and find solutions to overcome the actual limitations.

Microporous materials have the potential to represent a possible solution, as they allow the development of high conductivity channels in the composite solid electrolyte structure without compromising their mechanical and thermal properties. The application of MOFs, and particularly zeolites, in this field is not yet studied in much detail, but has gained interest in the last decade, demonstrating that this technology has the potential to become a reality in years to come. The lack of extensive and more systematic work in the use of these materials for battery applications, despite their interesting properties and tunability, leaves plenty of room for improvements and developments in the area.

Thus, there is still much work to do, as it is necessary to find the adequate materials to be used and the perfect balance between them in the composite solid electrolyte structure in order to get the specific properties required to optimize the composite solid electrolyte operation. The application of MOFs and zeolites in SPE can be an effective way to achieve this balance, as they can act as a thermal and mechanical stabilizer, which allows the application of other fillers exclusively for the improvement of the ionic conductivity. The possibility to design the desired structures is one of the biggest advantages of those materials, as it can be easily used to address specific issues associated with the lithium dendrite growth and the SEI formation, or even to create structures with intrinsic high ionic conductivity, or with a specific network of channels that facilitates the ion conduction. However, one of the challenges regarding the application of MOFs is the complexity in the synthesis of a structure with the desired properties due to the interplay between organic and inorganic elements. The systematic evaluation of the conduction and interfacial mechanisms will play a key role to better understand which materials and designs are more suited to solve the aforementioned issues. COFs are another promising material that is barely studied for SPEs, that can overcome some of the issues of the MOF technology, being a promising approach for future works.

Further, based on the increasing need for sustainable solutions, it is also important to be aware of the environmental concerns and seek natural materials (both polymers and fillers), enabling the operation of composite solid electrolyte with efficiency and low environmental impacts in the scope of the circular economy paradigms. The three-component approach can play a key role in this area when compared with the use of a single filler, which needs to be applied in large amounts, meaning that it needs to be produced in more quantities. The used of two specific fillers, each one with one specific function allows material response optimization and the reduction of the global amount of fillers used. On the other hand, in can lead to more complex recycling procedures. As many zeolites occur naturally, they can be considered an environmentally friendly option for the application in SPEs, when proper extraction and refinement procedures are used. If they are successfully combined with natural polymers, it is possible to fabricate a sustainable SPE, with low environmental impact. In the case of MOFs, despite the fact that they can provide improved performances, their environmental impact, particularly related to the materials and energy used in the production phase, when large amounts of material are to be synthesized have to be addressed. Thus, strategies to efficiently recycle and regenerate their structure, allowing for their reuse also have to be addressed in order to prove their technical and financial feasibility, together with a reduced environmental footprint.

The development of advanced processing techniques represents another field in which important improvements are expected in the next years, particularly with respect to additive manufacturing techniques. With additive manufacturing, it will be possible to develop batteries in a layer-by-layer approach and in any desired shapes and formats, resulting in the reduction of the interfacial problems and in the overall costs, due to the reduction of the wasted materials. The technologies mentioned above could surpass the LIB field, and be used in other energy storage technologies, such as lithium-sulfur, lithium-air, or even sodium batteries, that work with the same principles than those of LIBs, and that could allow a diversification of the 
energy storage options, which is an efficient way to reduce the excessive utilization of just one resource.

\section{Author contributions}

J. C. Barbosa: writing - original draft, writing - review \& editing. R. Gonçalves: writing - original draft, writing - review \& editing. C. M. Costa: writing - original draft, writing - review \& editing. V. de Zea Bermudez: writing - original draft, writing - review \& editing. A. F. Marijuan: writing - original draft, writing - review \& editing. Q. Zhang: writing - original draft, writing - review \& editing. S. Lanceros-Méndez: writing - original draft, writing review \& editing, funding acquisition.

\section{Conflicts of interest}

There are no conflicts to declare.

\section{Acknowledgements}

Work supported by the Portuguese Foundation for Science and Technology (FCT): projects UID/FIS/04650/2020, UID/QUI/00686/ 2019，UID/CTM/50025/2020，UID/QUI/50006/2020， PTDC/FISMAC/28157/2017, Grant SFRH/BD/140842/2018 (J. C. B.) and Investigator FCT Contracts CEECIND/00833/2017 (R. G.) and 2020.04028.CEECIND (C. M. C.). Financial support from the Basque Government Industry and Education Departments under the ELKARTEK and HAZITEK programs is also acknowledged.

\section{Notes and references}

1 R. P. Singh, A. Singh and V. Srivastava, Environmental issues surrounding human overpopulation, IGI Global, 2016.

2 Transforming our world: the 2030 Agenda for Sustainable Development, Report A/RES/70/1, UN General Assembly, 2015.

3 B. Scrosati, J. Hassoun and Y.-K. Sun, Energy Environ. Sci., 2011, 3287-3295, DOI: 10.1039/c1ee01388b.

4 B. Scrosati and J. Garche, J. Power Sources, 2010, 2419-2430, DOI: 10.1016/jjpowsour.2009.11.048.

5 A. Väyrynen and J. Salminen, J. Chem. Thermodyn., 2012, 80-85, DOI: $10.1016 /$ jjct201109005.

6 A. Volta, Philos. Trans. R. Soc. London, 1800, 90, 403-431.

7 H. Zhang, C. Li, G. G. Eshetu, S. Laruelle, S. Grugeon, K. Zaghib, C. Julien, A. Mauger, D. Guyomard, T. Rojo, N. Gisbert-Trejo, S. Passerini, X. Huang, Z. Zhou, P. Johansson and M. Forsyth, Angew. Chem., Int. Ed., 2020, 59, 534-538.

8 W. van Gool and N. A. T. O. S. A. Division, Fast Ion Transport in Solids: Solid State Batteries and Devices. Proceedings of the NATO Sponsored Advanced Study Institute on Fast Ion Transport in Solids, Solid State Batteries and Devices, Belgirate, Italy, 5-15 September 1972, North Holland Publishing Company, 1973.

9 Y. Nishi, Chem. Rec., 2001, 1, 406-413.
10 K. M. Abraham, J. Phys. Chem. Lett., 2015, 6, 830-844.

11 D. Miranda, A. Gören, C. M. Costa, M. M. Silva, A. M. Almeida and S. Lanceros-Méndez, Energy, 2019, 172, 68-78.

12 J. C. Barbosa, J. P. Dias, S. Lanceros-Mendez and C. M. Costa, Membranes, 2018, 8, 45.

13 C. M. Costa, M. M. Silva and S. Lanceros-Méndez, RSC Adv., 2013, 3, 11404-11417.

14 Q. Li, J. Chen, L. Fan, X. Kong and Y. Lu, Green Energy Environ., 2016, 1, 18-42.

15 Y. Yamada, J. Wang, S. Ko, E. Watanabe and A. Yamada, Nat. Energy, 2019, 4, 269-280.

16 D. Lisbona and T. Snee, Process Saf. Environ. Prot., 2011, 89, 434-442.

17 J. G. Kim, B. Son, S. Mukherjee, N. Schuppert, A. Bates, O. Kwon, M. J. Choi, H. Y. Chung and S. Park, J. Power Sources, 2015, 282, 299-322.

18 Q. Zhao, S. Stalin, C.-Z. Zhao and L. A. Archer, Nat. Rev. Mater., 2020, 5, 229-252.

19 J. Chen, Materials, 2013, 6, 156-183.

20 A. Sator, C. R. Hebd. Seances Acad. Sci., 1952, 234, 2283-2285.

21 E. Bekaert, L. Buannic, U. Lassi, A. Llordés and J. Salminen, in Emerging Nanotechnologies in Rechargeable Energy Storage Systems, ed. L. M. Rodriguez-Martinez and N. Omar, Elsevier, Boston, 2017, pp. 1-43, DOI: 10.1016/ B978-0-323-42977-1.00001-7.

22 C. M. Costa, Y.-H. Lee, J.-H. Kim, S.-Y. Lee and S. LancerosMéndez, Energy Storage Mater., 2019, 22, 346-375.

23 T. Okumura, S. Taminato, Y. Miyazaki, M. Kitamura, T. Saito, T. Takeuchi and H. Kobayashi, ACS Appl. Energy Mater., 2020, 3, 3220-3229.

24 R. DeWees and H. Wang, ChemSusChem, 2019, 12, 3713-3725.

25 Y. Li, H. Xu, P.-H. Chien, N. Wu, S. Xin, L. Xue, K. Park, Y.-Y. $\mathrm{Hu}$ and J. B. Goodenough, Angew. Chem., Int. Ed., 2018, 57, 8587-8591.

26 Q. Liu, Z. Geng, C. Han, Y. Fu, S. Li, Y.-B. He, F. Kang and B. Li, J. Power Sources, 2018, 389, 120-134.

27 J. Mindemark, M. J. Lacey, T. Bowden and D. Brandell, Prog. Polym. Sci., 2018, 81, 114-143.

28 M. B. Armand, J. M. Chabagno and M. J. Duclot, presented in part at the Fast ion transport in solids:electrodes and electrolytes, Amsterdam, Netherlands, 1979.

29 J. B. Goodenough, H.-P. Hong and J. Kafalas, Mater. Res. Bull., 1976, 11, 203-220.

30 J. Bates, N. Dudney, G. Gruzalski, R. Zuhr, A. Choudhury, C. Luck and J. Robertson, Solid State Ionics, 1992, 53, 647-654.

31 Y. Inaguma, C. Liquan, M. Itoh, T. Nakamura, T. Uchida, H. Ikuta and M. Wakihara, Solid State Commun., 1993, 86, 689-693.

32 D. E. Fenton, J. M. Parker and P. V. Wright, Polymer, 1973, 14, 589.

33 M. Armand, Solid State Ionics, 1983, 9-10, 745-754.

34 Z. Wang, B. Huang, H. Huang, L. Chen, R. Xue and F. Wang, Electrochim. Acta, 1996, 41, 1443-1446. 
35 H. S. Choe, J. Giaccai, M. Alamgir and K. M. Abraham, Electrochim. Acta, 1995, 40, 2289-2293.

36 A. Yoshino, Angew. Chem., Int. Ed., 2012, 51, 5798-5800.

37 B. Scrosati and J. Garche, J. Power Sources, 2010, 195, 2419-2430.

38 F. Wu, K. Zhang, Y. Liu, H. Gao, Y. Bai, X. Wang and C. Wu, Energy Storage Mater., 2020, 33, 26-54.

39 R. Chen, Q. Li, X. Yu, L. Chen and H. Li, Chem. Rev., 2019, 120, 6820-6877.

40 Q. Zhang, K. Liu, F. Ding and X. Liu, Nano Res., 2017, 10, 4139-4174.

41 J. Li, C. Ma, M. Chi, C. Liang and N. J. Dudney, Adv. Energy Mater., 2015, 5, 1401408.

42 A. Stephan and K.-S. Nahm, Polymer, 2006, 47, 5952-5964.

43 Y. Kato, S. Hori, T. Saito, K. Suzuki, M. Hirayama, A. Mitsui, M. Yonemura, H. Iba and R. Kanno, Nat. Energy, 2016, 1, 16030.

44 J. Y. Song, Y. Wang and C. Wan, J. Power Sources, 1999, 77, 183-197.

45 R. Koerver, W. Zhang, L. de Biasi, S. Schweidler, A. O. Kondrakov, S. Kolling, T. Brezesinski, P. Hartmann, W. G. Zeier and J. Janek, Energy Environ. Sci., 2018, 11, 2142-2158.

46 L. Xu, S. Tang, Y. Cheng, K. Wang, J. Liang, C. Liu, Y.-C. Cao, F. Wei and L. Mai, Joule, 2018, 2, 1991-2015.

47 P. Barai, K. Higa and V. Srinivasan, Phys. Chem. Chem. Phys., 2017, 19, 20493-20505.

48 A. Wang, S. Kadam, H. Li, S. Shi and Y. Qi, npj Comput. Mater., 2018, 4, 15.

49 H. Lv, X. Huang and Y. Liu, Ionics, 2020, 26, 1749-1770.

50 P. Hartmann, T. Leichtweiss, M. R. Busche, M. Schneider, M. Reich, J. Sann, P. Adelhelm and J. Janek, J. Phys. Chem. C, 2013, 117, 21064-21074.

51 R. Bhattacharyya, B. Key, H. Chen, A. S. Best, A. F. Hollenkamp and C. P. Grey, Nat. Mater., 2010, 9, 504-510.

52 D. Lin, Y. Liu and Y. Cui, Nat. Nanotechnol., 2017, 12, 194-206.

53 C.-Z. Zhao, X.-Q. Zhang, X.-B. Cheng, R. Zhang, R. Xu, P.Y. Chen, H.-J. Peng, J.-Q. Huang and Q. Zhang, Proc. Natl. Acad. Sci. U. S. A., 2017, 114, 11069.

54 S. Bhattacharya, A. R. Riahi and A. Alpas, Carbon, 2013, 67, 592-606.

55 F. Orsini, A. Pasquier, B. Beaudoin, J.-M. Tarascon, M. Trentin, N. Langenhuizen, E. D. Beer and P. H. L. Notten, J. Power Sources, 1998, 76, 19-29.

56 J. Li, C. Ma, M. Chi, C. Liang and N. J. Dudney, Adv. Energy Mater., 2015, 5, 1401408.

57 S. Li, S.-Q. Zhang, L. Shen, Q. Liu, J.-B. Ma, W. Lv, Y.-B. He and Q.-H. Yang, Adv. Sci., 2020, 7, 1903088.

58 W. M. Wang, Adv. Mater. Res., 2012, 571, 13-16.

59 R. C. Agrawal and G. P. Pandey, J. Phys. D: Appl. Phys., 2008, 41, 223001.

60 P. Yao, H. Yu, Z. Ding, Y. Liu, J. Lu, M. Lavorgna, J. Wu and X. Liu, Front. Chem., 2019, 7, 522.

61 Z. Xue, D. He and X. Xie, J. Mater. Chem. A, 2015, 3, 19218-19253.
62 Z. Zou, Y. Li, Z. Lu, D. Wang, Y. Cui, B. Guo, Y. Li, X. Liang, J. Feng, H. Li, C.-W. Nan, M. Armand, L. Chen, K. Xu and S. Shi, Chem. Rev., 2020, 120, 4169-4221.

63 T. Famprikis, P. Canepa, J. A. Dawson, M. S. Islam and C. Masquelier, Nat. Mater., 2019, 18, 1278-1291.

64 D. Bresser, S. Lyonnard, C. Iojoiu, L. Picard and S. Passerini, Mol. Systems Des. Eng., 2019, 4, 779-792.

65 Z. Gadjourova, Y. G. Andreev, D. P. Tunstall and P. G. Bruce, Nature, 2001, 412, 520-523.

66 R. Chen, W. Qu, X. Guo, L. Li and F. Wu, Mater. Horiz., 2016, 3, 487-516.

67 Y. Zhang, X. Wang, W. Feng, Y. Zhen, P. Zhao, C. Ziming and L. Li, Ionics, 2018, 25, 1471-1480.

68 S. Chen, K. Wen, J. Fan, Y. Bando and D. Golberg, J. Mater. Chem. A, 2018, 6, 11631-11663.

69 I. Osada, H. de Vries, B. Scrosati and S. Passerini, Angew. Chem., Int. Ed., 2016, 55, 500-513.

70 Y. Tominaga, Y. Kinno and K. Kimura, Electrochim. Acta, 2019, 302, 286-290.

71 L. Long, S. Wang, M. Xiao and Y. Meng, J. Mater. Chem. A, 2016, 4, 10038-10069.

72 M. Manuela Silva, P. Barbosa, A. Evans and M. J. Smith, Solid State Sci., 2006, 8, 1318-1321.

73 V. Deimede and C. Elmasides, Energy Technol., 2015, 3, 453-468.

74 P. V. Wright, Br. Polym. J., 1975, 7, 319-327.

75 P. Lun, Z. Chen, Z. Zhang, S. Tan and D. Chen, RSC Adv., 2018, 8, 34232-34240.

76 D. Shang, J. Fu, Q. Lu, L. Chen, J. Yin, X. Dong, Y. Xu, R. Jia, S. Yuan, Y. Chen and W. Deng, Solid State Ionics, 2018, 319, 247-255.

77 X. Zhang, B.-Q. Xu, Y.-H. Lin, Y. Shen, L. Li and C.-W. Nan, Solid State Ionics, 2018, 327, 32-38.

78 K. Kimura and Y. Tominaga, ChemElectroChem, 2018, 5, 4008-4014.

79 G. Guzmán-González, H. J. Ávila-Paredes, E. Rivera and I. González, ACS Appl. Mater. Interfaces, 2018, 10, 30247-30256.

80 M. Xie, L. Li, K. Yuan, Y. Ma and B. Liu, J. Mater. Sci.: Mater. Electron., 2019, 30, 2030-2036.

81 Y. Lim, H.-A. Jung and H. Hwang, Energies, 2018, 11, 2559.

82 A. L. Ahmad, U. R. Farooqui and N. A. Hamid, RSC Adv., 2018, 8, 25725-25733.

83 M. Sohaimy and M. I. N. Mohamad Isa, Appl. Mech. Mater., 2015, 719-720, 67-72.

84 P. Perumal, C. Selvin, S. Subramanian, S. Pazhaniswamy, P. A. Karuthedath, M. Vijayan and R. Devi, Polym. Degrad. Stab., 2018, 159, 43-53.

85 S. Side, D. Pratiwi and F. Hadianita, AIP Conf. Proc., 2018, 2030, 020285, DOI: 10.1063/1.5066926.

86 R. Chitra, P. Sathya, S. Selvasekarapandian, S. Monisha, V. Moniha and S. Meyvel, Ionics, 2019, 25, 2147-2157.

87 N. Boaretto, L. Meabe, M. Martinez-Ibañez, M. Armand and H. Zhang, J. Electrochem. Soc., 2020, 167, 070524.

88 Y. Zhang, X. Wang, W. Feng, Y. Zhen, P. Zhao, L. Li and C. Ziming, J. Solid State Electrochem., 2019, 23, 749-758. 
89 D. Li, D. Qin, F. Nie, L. Wen and L. Xue, J. Mater. Sci., 2018, 53, 11038-11049.

90 S. Choudhury, S. Stalin, Y. Deng and L. A. Archer, Chem. Mater., 2018, 30, 5996-6004.

91 X. Li, X. Wang, D. Shao, L. Liu and L. Yang, J. Appl. Polym. Sci., 2019, 136, 47498.

92 A. L. Ahmad, U. R. Farooqui and N. A. Hamid, Electrochim. Acta, 2018, 283, 842-849.

93 J. Nunes-Pereira, C. M. Costa, R. Leones, M. M. Silva and S. Lanceros-Méndez, Solid State Ionics, 2013, 249-250, 63-71.

94 R. Whba, T. K. Lee, M. Su'ait, M. Y. Abd. Rahman and A. Ahmad, Arabian J. Chem., 2018, 13, 3351-3361.

95 A. Arya and A. L. Sharma, J. Phys. D: Appl. Phys., 2018, 51, 045504.

96 H. Zeng, X. Ji, F. Tsai, Q. Zhang, T. Jiang, R. K. Y. Li, H. Shi, S. Luan and D. Shi, Solid State Ionics, 2018, 320, 92-99.

97 Z. Wei, S. Chen, J. Wang, Z. Wang, Z. Zhang, X. Yao, Y. Deng and X. Xu, J. Mater. Chem. A, 2018, 6, 13438-13447.

98 G. Yang, B. Fan, F. Liu, F. Yao and Q. Wang, Energy Technol., 2018, 6, 2319-2325.

99 A. Wang, H. Xu, F. Liu, X. Liu, S. Wang, Q. Zhou, J. Chen, S. Yang and L. Zhang, Energy Technol., 2018, 6, 326-332.

100 V. Di Noto, M. Fauri, M. Vittadello, S. Lavina and S. Biscazzo, Electrochim. Acta, 2001, 46, 1587-1594.

101 Y. Lin, X. Wang, J. Liu and J. D. Miller, Nano Energy, 2017, 31, 478-485.

102 F. Zhu, H. Bao, X. Wu, Y. Tao, C. Qin, Z. Su and Z. Kang, ACS Appl. Mater. Interfaces, 2019, 11, 43206-43213.

103 E. M. Miner and M. Dincă, Philos. Trans. R. Soc., A, 2019, 377, 20180225.

104 Z. Liu, P. Liu, L. Tian, J. Xiao, R. Cui and Z. Liu, Chem. Commun., 2020, 56, 14629-14632.

105 T. Chen, S. Chen, Y. Chen, M. Zhao, D. Losic and S. Zhang, Mater. Chem. Front., 2021, 5, 1771-1794.

106 E. M. Miner, S. S. Park and M. Dincă, J. Am. Chem. Soc., 2019, 141, 4422-4427.

107 L. Sun, M. G. Campbell and M. Dincă, Angew. Chem., Int. Ed., 2016, 55, 3566-3579.

108 R. Zhao, Y. Wu, Z. Liang, L. Gao, W. Xia, Y. Zhao and R. Zou, Energy Environ. Sci., 2020, 13, 2386-2403.

109 S. K. Bhardwaj, N. Bhardwaj, R. Kaur, J. Mehta, A. L. Sharma, K.-H. Kim and A. Deep, J. Mater. Chem. A, 2018, 6, 14992-15009.

110 W.-H. Li, W.-H. Deng, G.-E. Wang and G. Xu, Energy Chem., 2020, 2, 100029.

111 W. Li, J. Liu and D. Zhao, Nat. Rev. Mater., 2016, 1, 16023.

112 H. Zhao, L. Sheng, L. Wang, H. Xu and X. He, Energy Storage Mater., 2020, 33, 360-381.

113 N. Yanai, T. Uemura, S. Horike, S. Shimomura and S. Kitagawa, Chem. Commun., 2011, 47, 1722-1724.

114 L. M. Martínez, T. S. Ivanova, B. Louis and J. A. Odriozola, in Zeolites and Metal-Organic Frameworks, ed. V. Blay, L. F. Bobadilla and A. C. García, Amsterdam University Press, 2018, pp. 25-52, DOI: 10.2307/j.ctvcmxprm.5.

115 V. Valtchev and S. Mintova, in Zeolites and Metal-Organic Frameworks, ed. V. Blay, L. F. Bobadilla and A. C. García,
Amsterdam University Press, 2018, pp. 13-24, DOI: 10.2307/j.ctvemxprm.4.

116 R. Agrawal and G. P. Pandey, J. Phys. D: Appl. Phys., 2008, 41, 223001.

117 R. E. Sousa, C. M. Costa and S. Lanceros-Méndez, ChemSusChem, 2015, 8, 3539-3555.

118 L. Zeng, P. Li, Y. Yao, B. Niu, S. Niu and B. Xu, Mater. Today Nano, 2020, 12, 100094.

119 J. Rouquerol, D. Avnir, C. W. Fairbridge, D. H. Everett, J. M. Haynes, N. Pernicone, J. D. F. Ramsay, K. S. W. Sing and K. K. Unger, Pure Appl. Chem., 1994, 66, 1739-1758.

120 F. Akhtar, L. Andersson, S. Ogunwumi, N. Hedin and L. Bergström, J. Eur. Ceram. Soc., 2014, 34, 1643-1666.

121 S. Tang, W. Guo and Y. Fu, Adv. Energy Mater., 2021, 11, 2000802.

122 S. L. James, Chem. Soc. Rev., 2003, 32, 276-288.

123 O. M. Yaghi, G. Li and H. Li, Nature, 1995, 378, 703-706.

124 P. Z. Moghadam, A. Li, S. B. Wiggin, A. Tao, A. G. P. Maloney, P. A. Wood, S. C. Ward and D. FairenJimenez, Chem. Mater., 2017, 29, 2618-2625.

125 X. Li, X. Yang, H. Xue, H. Pang and Q. Xu, Energy Chem., 2020, 2, 100027.

126 J. Kim, H. Cho and W.-S. Ahn, Catal. Surv. Asia, 2012, 16, 106-119.

127 R. C. G. Frem, G. Arroyos, J. B. D. S. Flor, R. C. Alves, G. N. Lucena, C. M. D. Silva and M. F. Coura, Química Nova, 2018, 41, 1178-1191.

128 O. K. Farha, I. Eryazici, N. C. Jeong, B. G. Hauser, C. E. Wilmer, A. A. Sarjeant, R. Q. Snurr, S. T. Nguyen, A. Ö. Yazaydın and J. T. Hupp, J. Am. Chem. Soc., 2012, 134, 15016-15021.

129 T. Tian, Z. Zeng, D. Vulpe, M. E. Casco, G. Divitini, P. A. Midgley, J. Silvestre-Albero, J.-C. Tan, P. Z. Moghadam and D. Fairen-Jimenez, Nat. Mater., 2018, 17, 174-179.

130 N. S. Bobbitt, M. L. Mendonca, A. J. Howarth, T. Islamoglu, J. T. Hupp, O. K. Farha and R. Q. Snurr, Chem. Soc. Rev., 2017, 46, 3357-3385.

131 M. H. Teplensky, M. Fantham, P. Li, T. C. Wang, J. P. Mehta, L. J. Young, P. Z. Moghadam, J. T. Hupp, O. K. Farha, C. F. Kaminski and D. Fairen-Jimenez, J. Am. Chem. Soc., 2017, 139, 7522-7532.

132 S. M. J. Rogge, A. Bavykina, J. Hajek, H. Garcia, A. I. OlivosSuarez, A. Sepúlveda-Escribano, A. Vimont, G. Clet, P. Bazin, F. Kapteijn, M. Daturi, E. V. Ramos-Fernandez, F. X. Llabrés i Xamena, V. Van Speybroeck and J. Gascon, Chem. Soc. Rev., 2017, 46, 3134-3184.

133 Z. Hu, B. J. Deibert and J. Li, Chem. Soc. Rev., 2014, 43, 5815-5840.

134 T. Qiu, Z. Liang, W. Guo, H. Tabassum, S. Gao and R. Zou, ACS Energy Lett., 2020, 5, 520-532.

135 Z. Wang, R. Tan, H. Wang, L. Yang, J. Hu, H. Chen and F. Pan, Adv. Mater., 2018, 30, 1704436.

136 C.-C. Sun, A. Yusuf, S.-W. Li, X.-L. Qi, Y. Ma and D.-Y. Wang, Chem. Eng. J., 2021, 414, 128702.

137 Z. Lei, J. Shen, J. Wang, Q. Qiu, G. Zhang, S.-S. Chi, H. Xu, S. Li, W. Zhang, Y. Zhao, Y. Deng and C. Wang, Chem. Eng. J., 2021, 412, 128733. 
138 W. Wen, Z. Wang, A. Wang, Q. Zeng, P. Chen, X. Wen, Z. Li, Z. Li, W. Liu and L. Zhang, Energy Technol., 2021, 9, 2000808.

139 H. Huo, B. Wu, T. Zhang, X. Zheng, L. Ge, T. Xu, X. Guo and X. Sun, Energy Storage Mater., 2019, 18, 59-67.

140 Z. Zhang, J.-H. You, S.-J. Zhang, C.-W. Wang, Y. Zhou, J.-T. Li, L. Huang and S.-G. Sun, ChemElectroChem, 2020, 7, 1125-1134.

141 L. Liu and C. Sun, ChemElectroChem, 2020, 7, 707-715.

142 N. Angulakshmi, R. S. Kumar, M. A. Kulandainathan and A. M. Stephan, J. Phys. Chem. C, 2014, 118, 24240-24247.

143 Z. Wang, S. Wang, A. Wang, X. Liu, J. Chen, Q. Zeng, L. Zhang, W. Liu and L. Zhang, J. Mater. Chem. A, 2018, 6, 17227-17234.

144 C. Yuan, J. Li, P. Han, Y. Lai, Z. Zhang and J. Liu, J. Power Sources, 2013, 240, 653-658.

145 D. E. Mathew, S. Gopi, M. Kathiresan, A. M. Stephan and S. Thomas, Electrochim. Acta, 2019, 319, 189-200.

146 C. Gerbaldi, J. R. Nair, M. A. Kulandainathan, R. S. Kumar, C. Ferrara, P. Mustarelli and A. M. Stephan, J. Mater. Chem. A, 2014, 2, 9948-9954.

147 S. Suriyakumar, S. Gopi, M. Kathiresan, S. Bose, E. B. Gowd, J. R. Nair, N. Angulakshmi, G. Meligrana, F. Bella, C. Gerbaldi and A. M. Stephan, Electrochim. Acta, 2018, 285, 355-364.

148 Z. Zhang, Y. Huang, H. Gao, J. Hang, C. Li and P. Liu, J. Membr. Sci., 2020, 598, 117800.

149 J.-F. Wu and X. Guo, J. Mater. Chem. A, 2019, 7, 2653-2659. 150 R. Kumar, M. Raja, A. Kulandainathan and A. Stephan, RSC Adv., 2014, 4, 26171.

151 S. Suriyakumar, M. Kanagaraj, N. Angulakshmi, M. Kathiresan, K. S. Nahm, M. Walkowiak, K. Wasiński, P. Półrolniczak and A. M. Stephan, RSC Adv., 2016, 6, 97180-97186.

152 K. Zhu, Y. Liu and J. Liu, RSC Adv., 2014, 4, 42278-42284.

153 Z. Wang, H. Zhou, C. Meng, W. Xiong, Y. Cai, P. Hu, H. Pang and A. Yuan, ACS Appl. Energy Mater., 2020, 3, 4265-4274.

154 N. Angulakshmi, Y. Zhou, S. Suriyakumar, R. B. Dhanalakshmi, M. Satishrajan, S. Alwarappan, M. H. Alkordi and A. M. Stephan, ACS Omega, 2020, 5, 7885-7894.

155 J. Yang, L. Shao, X. Wang, Y. Yang, Z. Tian, W. Chen, G. Zhang and C. Shen, J. Alloys Compd., 2020, 845, 155179.

156 J. Dong, X. Han, Y. Liu, H. Li and Y. Cui, Angew. Chem., 2020, 132, 13826-13837.

157 P. J. Waller, F. Gándara and O. M. Yaghi, Acc. Chem. Res., 2015, 48, 3053-3063.

158 G. Zhang, Y.-l. Hong, Y. Nishiyama, S. Bai, S. Kitagawa and S. Horike, J. Am. Chem. Soc., 2019, 141, 1227-1234.

159 D. Dong, H. Zhang, B. Zhou, Y. Sun, H. Zhang, M. Cao, J. Li, H. Zhou, H. Qian, Z. Lin and H. Chen, Chem. Commun., 2019, 55, 1458-1461.

160 A. Corma, J. Catal., 2003, 216, 298-312.

161 S. Ozaydin, G. Kocer and A. Hepbasli, Energy Sources, Part A, 2006, 28, 1425-1431.
162 E. M. Flanigen, R. W. Broach and S. T. Wilson, Zeolites in Industrial Separation and Catalysis, 2010.

163 R. M. Barrer, J. Chem. Soc., 1948, 2158-2163, DOI: 10.1039/ JR9480002158.

164 R. M. Barrer, J. Chem. Soc., 1948, 127-132, DOI: 10.1039/ JR9480000127.

165 B. Jha and D. N. Singh, Basics of Zeolites, in Fly Ash Zeolites, Advanced Structured Materials, Springer, Singapore, 2016, vol. 78, DOI: 10.1007/978-981-10-1404-8_2.

166 W. J. Roth, P. Nachtigall, R. E. Morris and J. Čejka, Chem. Rev., 2014, 114, 4807-4837.

167 A. R. Bertão, N. Pires, A. M. Fonseca, O. S. G. P. Soares, M. F. R. Pereira, T. Dong and I. C. Neves, Sens. Actuators, B, 2018, 261, 66-74.

168 T. Ennaert, J. Van Aelst, J. Dijkmans, R. De Clercq, W. Schutyser, M. Dusselier, D. Verboekend and B. F. Sels, Chem. Soc. Rev., 2016, 45, 584-611.

169 M. Pera-Titus, Chem. Rev., 2014, 114, 1413-1492.

170 J. Wei, Q. Ge, R. Yao, Z. Wen, C. Fang, L. Guo, H. Xu and J. Sun, Nat. Commun., 2017, 8, 15174.

171 R. Zhang, N. Liu, Z. Lei and B. Chen, Chem. Rev., 2016, 116, 3658-3721.

172 Y. Meng, H. C. Genuino, C.-H. Kuo, H. Huang, S.-Y. Chen, L. Zhang, A. Rossi and S. L. Suib, J. Am. Chem. Soc., 2013, 135, 8594-8605.

173 P. Swenson, B. Tanchuk, E. Bastida, W. An and S. M. Kuznicki, Desalination, 2012, 286, 442-446.

174 N. Yu, R. Z. Wang and L. W. Wang, Prog. Energy Combust. Sci., 2013, 39, 489-514.

175 Q. Sun, N. Wang, Q. Bing, R. Si, J. Liu, R. Bai, P. Zhang, M. Jia and J. Yu, Chem, 2017, 3, 477-493.

176 B. Kaur, R. Srivastava and B. Satpati, ACS Catal., 2016, 6, 2654-2663.

177 N. Kim, H. Park, N. Yoon and J. K. Lee, ACS Nano, 2018, 12, 3853-3864.

178 H. Park, N. Yoon, D. Kang, C. Young and J. K. Lee, Electrochim. Acta, 2020, 357, 136870.

179 M. Badini Pourazar, T. Mohammadi, M. R. Jafari Nasr, O. Bakhtiari and M. Javanbakht, J. Appl. Polym. Sci., 2020, 137, 49367.

180 Y. Li, X. Wang, J. Liang, K. Wu, L. Xu and J. Wang, Polymers, 2020, 12, 746.

181 J. Zhang, Y. Xiang, M. I. Jamil, J. Lu, Q. Zhang, X. Zhan and F. Chen, J. Membr. Sci., 2018, 564, 753-761.

182 E. Shekarian, M. R. Jafari Nasr, T. Mohammadi, O. Bakhtiari and M. Javanbakht, J. Appl. Polym. Sci., 2019, 136, 47841.

183 J. Xu, X. Xiao, S. Zeng, M. Cai and M. W. Verbrugge, ACS Appl. Energy Mater., 2018, 1, 7237-7243.

184 X. Dong, W. Mi, L. Yu, Y. Jin and Y. S. Lin, Microporous Mesoporous Mater., 2016, 226, 406-414.

185 J. H. Kim, H. Jamal, F. Khan, S. Hyun and S. W. Min, J. Mater. Chem. A, 2021, 9, 4126-4137. 